\title{
Operational relationships between NOAA-advanced very high resolution radiometer vegetation indices and daily fraction of absorbed photosynthetically active radiation, established for Sahelian vegetation canopies
}

\author{
A. Bégué \\ Centre de Coopération Internationale de Recherche Agronomique pour le Développement, \\ Département des Cultures Annuelles, Maison de la Télédétection, Montpellier, France
}

\section{R. Myneni}

Biospheric Sciences Branch, NASA Goddard Space Flight Center, Greenbelt, Maryland

\begin{abstract}
To improve the estimation of primary production at a regional scale, an assessment of the utility of fraction of absorbed photosynthetically active radiation (fAPAR) estimated from spectral vegetation indices (VI) for the case of the Sahelian vegetation was studied. Simulations using a three-dimensional radiative transfer model were conducted for two types of structurally distinct vegetation canopies: millet crop (regularly distributed clumps of vegetation over bare soil) and savanna (mixture of a grass layer and a sparse woody layer). A realistic range of values is extracted for each vegetation input variable (leaf area index, ground cover, height and spatial distribution) from published literature. Bidirectional reflectance factors were calculated in the NOAA-advanced very high resolution radiometer (AVHRR) spectral bands for a geometric configuration representative of the NOAA satellite series. Two vegetation indices were tested : normalized difference vegetation index (NDVI) and modified soil adjusted vegetation index (MSAVI). The simulations indicate that the fAPAR-VI relationship is sensitive to the geometry of measurement and soil optical properties, especially in the case of a millet crop. Simple linear models that include this variability and are directly applicable to atmospherically corrected AVHRR data are proposed, and the error of estimation of fAPAR is evaluated. MSAVI gives better results, especially when the brightness of soil is known. For natural vegetation the relationship between fAPAR and MSAVI is then reduced to a coefficient that is a constant $(\sim 2.2)$. For millet canopies this coefficient is a function of Sun and view angles. Finally, the utility of our approach is illustrated with two examples of fAPAR-VI relationships applied to a NOAA time series.
\end{abstract}

\section{Introduction}

Global circulation models (GCM) need accurate vegetation information at a global scale to simulate and predict climate changes. Leaf area index (LAI), absorbed photosynthetically active radiation (APAR), or biomass estimates are of interest. Some attempts have been made to establish these variables from NOAA images with simple biomass production modeling. The basic idea is first to define and identify classes of vegetation, generally from existing vegetation maps such as Matthews's [1983] vegetation and land use map. Then each vegetation type can be assigned morphological, op-

Copyright 1996 by the American Geophysical Union.

Paper number 96JD01621.

0148-0227/96/96JD-01621\$09.00 tical, and/or physiological properties obtained from the ecological literature. For example, Ruimy et al. [1994] introduced a biome-dependent conversion efficiency ( $\mathrm{g}$ of dry matter per MJ of APAR) but used a single global linear relationship to estimate the fraction of APAR (fAPAR) from NOAA vegetation index (VI). Recently, Sellers et al. [1994] refined the fAPAR estimation by proposing four biome-dependent fAPAR-VI relationships. In fact, almost all previous publications on the subject show that the fAPAR-VI relationship varies significantly with the structure of the canopy and the background optical properties [Baret and Olioso, 1989; Goward and Huemmrich, 1992]. More recent studies on sparse canopies have shown that the relationship was also sensitive to the geometric configuration of the measurement [Bégué, 1993].

It is obvious that the fAPAR-VI experimental relationships are related to a particular vegetation canopy 
and specific measurement environment (time of the measurement, type of radiometer and background) so that they cannot be used at a larger scale. In the same way the relationships derived from radiative transfer modeling are not adequate at a global scale, because they are generally established for homogeneous canopies, an oversimplification of the structure of the vegetation in most regions of the world. A recent study [Myneni and Williams, 1994] proposed a relationship derived from a three-dimensional radiative transfer model, to represent a large-canopy problem parameter space (ground cover, leaf area, leaf orientation, and optical properties). Unfortunately, this relationship has been established only for nadir viewing and soils of moderate brightness, posing a limitation for an operational use. Furthermore, the VI is related to the instantaneous fAPAR and not to the daily fAPAR ( fAPAR $_{d}$ ), which is generally the variable of interest in terms of primary production. For homogeneous vegetation canopies, instantaneous and daily fAPAR are very close, but for canopies with strong directional effects the difference between instantaneous and daily fAPAR can be quite significant. Nevertheless, the interest of most experimental and modeling studies (reviewed by Ruimy et al. [1994]) is to show that fAPAR and VI (especially the normalized difference vegetation index, or NDVI) are near linearly related and then should be scale invariant.

Because of the lack of reliable fAPAR-VI relationships, global modelers prefer to establish their own relationship directly from the satellite images. The assumption is that fAPAR and VI are linearly related and that the coefficients of the relationships can be determined with the following additional assumptions: fAPAR equal to 0 is associated with the minimal VI value of the images, and fAPAR equal or close to 1 is associated with a maximal value of VI, calculated or obtained from satellite imagery over dense vegetation. The regressions thus established from NOAA advanced very high resolution radiometer (AVHRR) imagery are shown in Figure 1. The range of these relations is very large. Part of it can be explained by image processing (type of product and atmospheric correction), but most of the variability is caused by the choice (location and time) of the minimal and maximal values of VI.

To monitor pasture land in Mali with NOAA AVHRR, Hanan et al. [1995] simulated theoretical relationships between fAPAR $_{d}$ and NDVI with the SAIL model, duplicating the geometry and environment of NOAA acquisition (such as Sun-sensor geometric configuration and optical properties of the soil corresponding to the images before the rainy season). These relationships were then applied directly to the atmospherically corrected NOAA time series. This approach of using radiative transfer modeling in an operational method is a step beyond the empirical methods. In this paper we attempt a similar approach by establishing fAPAR $_{d}$-VI relationships from radiative transfer modeling and applying these relations to corrected NOAA images over the Sahel. These relationships are calculated with a threedimensional (3-D) model of radiative transfer [Myneni

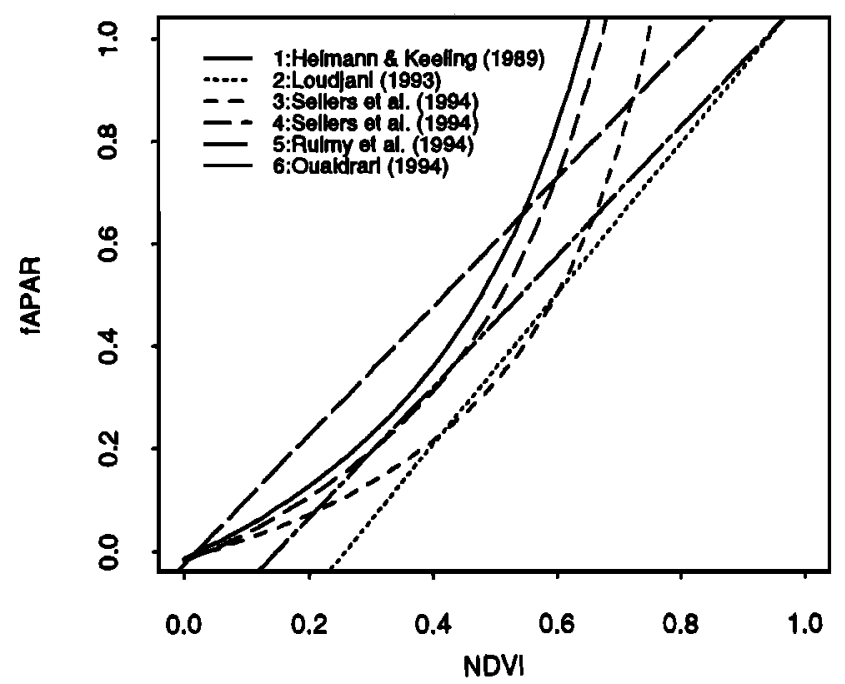

Figure 1. The fAPAR-VI relationships established from NOAA imagery. For consistency, the fAPAR-SR $(\mathrm{SR}=\mathrm{NIR} / \mathrm{R})$ relationships are plotted after variable transformation from SR to NDVI: 1 : fAPAR $=0.279$ SR - 0.294 ; global; fAPAR $=0$ corresponds to the mean SR of Alaska region in winter, and fAPAR $=1$ corresponds to a value given by the Kubelka-Munk theory (uncorrected GVI). 2: fAPAR $=1.468$ NDVI - 0.381; West Africa (between 1986 and 1991); fAPAR $=0$ and 0.95 correspond to the maximum NDVI of the desert and the NDVI of the equatorial forest, respectively (corrected GVI). 3: fAPAR $=0.171 \mathrm{SR}-0.186$; global tall vegetation; fAPAR $=0$ and 0.95 correspond to $5 \%$ desert NDVI value and $98 \%$ tall vegetation NDVI, respectively $\left(1^{\circ} \times 1^{\circ} \mathrm{NDVI}\right) .4$ : fAPAR $=0.248 \mathrm{SR}-0.268$; global short vegetation; fAPAR $=0$ and 0.95 correspond to $5 \%$ desert NDVI value and $98 \%$ short vegetation NDVI, respectively $\left(1^{\circ} \times 1^{\circ} \mathrm{NDVI}\right) .5:$ fAPAR $=1.25 \mathrm{NDVI}$ 0.025 ; global; fAPAR $=0$ corresponds to the mean minimum of the tropical deserts NDVI, and fAPAR $=1$ corresponds to the maximum NDVI of the equatorial forest (corrected GVI). 6: fAPAR = 1.27 NDVI - 0.190; Niger; fAPAR $=0$ corresponds to the NDVI before the rainy season, and fAPAR $=0.95$ corresponds to NDVI equal to 0.9 (corrected LAC data).

et al., 1990; Myneni and Asrar, 1993] capable of simulating most of the Sahelian vegetation, which is sparse and heterogeneous in nature. This model is based on an accurate numerical solution of the 3-D radiative transfer equation by the method of discrete ordinates.

The 3-D radiative transfer model is first described, and then realistic Sahelian vegetation, soil, and environmental inputs are listed and documented. Simulations of fAPAR-VI are presented, and the value of the linear regression coefficients and the RMSE are discussed according to the geometry of the measurement, for two types of vegetation canopy (crop and natural vegetation) and for two different vegetation indices (NDVI and modified soil adjusted vegetation index, or MSAVI). Attempts to simplify the fAPAR-VI relationship are made. Finally, an application of these calculated semiempirical relationships to a NOAA time series over the $1^{\circ} \times 1^{\circ}$ 
HAPEX-Sahel site [Goutorbe et al., 1994] is presented and discussed in light of ground observations.

\section{Three-Dimensional Radiative Transfer Model}

\section{The Model}

We consider a vegetated surface of indeterminate ground cover (partial or complete). We are interested in the angular distribution of the radiance field at the top of the vegetation canopy in the wavelength intervals $0.58-0.68 \mu \mathrm{m}$ and $0.72-1.10 \mu \mathrm{m}$ corresponding to the red and near-infrared AVHR.R channels, respectively. Additionally, the fraction of incident photosynthetically active radiation (0.4-0.7 $\mu \mathrm{m}[\mathrm{McCree}, 1972])$ absorbed by the canopy is of interest. This physical problem can be posed in terms of radiative transfer theory as follows.

Consider a 3-D vegetation canopy of finite physical dimensions $\left(X_{s}, Y_{s}, Z_{s}\right)$ along three spatial coordinates idealized as a turbid medium. The steady state monochromatic intensity function $I(\mathbf{r}, \hat{\Omega})$ in the absence of polarization, frequency shifting interactions and emission is given by the radiative transfer equation:

$$
\begin{array}{r}
\hat{\Omega} \bullet \nabla I(\mathbf{r}, \hat{\Omega})+\sigma(\mathbf{r}, \hat{\Omega}) I(\mathbf{r}, \hat{\Omega}) \\
=\int_{4 \pi} d \hat{\Omega}^{\prime} \sigma_{s}\left(\mathbf{r}, \hat{\Omega}^{\prime} \rightarrow \hat{\Omega}\right) I\left(\mathbf{r}, \hat{\Omega}^{\prime}\right)
\end{array}
$$

The position vector (r) denotes the spatial location $(x, y, z)$ with $\left(0 \leq x \leq X_{s}\right),\left(0 \leq y \leq Y_{s}\right)$, and $(0 \leq$ $\left.z \leq Z_{s}\right)$. The unit direction vector $\hat{\Omega}$ has an azimuthal angle $\phi$ measured anticlockwise from the positive $x$ axis that is directed north and a polar angle $\theta=\cos ^{-1} \mu$ with respect to the outward normal. The operator $[\hat{\Omega} \bullet \nabla]$ denotes the spatial derivative along the direction of photon travel. The total interaction cross section $\sigma$ and the differential scattering cross section $\sigma_{s}$ depend on the leaf area density distribution, the probability density of leaf normal orientation, and the leaf-scattering phase function. These functions characterize the architecture and optics of the leaf canopy, and their parameterization is discussed later. The total intensity at a point in the phase space is $I(\mathbf{r}, \hat{\Omega})=I^{o}(\mathbf{r}, \hat{\Omega})+I^{c}(\mathbf{r}, \hat{\Omega})$, with $I^{\circ}$ the intensity of uncollided radiation field and $I^{c}$ the intensity of photons scattered one or more times in the canopy.

The equation of transfer for the uncollided radiation field is

$$
\hat{\Omega} \bullet \nabla I^{o}(\mathbf{r}, \hat{\Omega})+\sigma(\mathbf{r}, \hat{\Omega}) I^{o}(\mathbf{r}, \hat{\Omega})=0
$$

Let the leaf canopy be illuminated from above by both a monodirectional solar component (in the direction $\left.\hat{\Omega}_{o} \sim\left(\mu_{o}, \phi_{o}\right), \mu_{o}<0\right)$ of intensity $I_{o}$ and diffuse radiation from the sky (in the direction $\hat{\Omega} \sim(\mu, \phi), \mu<0$ ) of intensity $I_{d}$. The diffuse component is assumed isotropic. The incident radiation field at the top of the canopy $(x, y, 0)$ is then

$$
I_{o}(x, y, 0 ; \hat{\Omega})=I_{d}(\hat{\Omega})+I_{o} \delta\left(\hat{\Omega}-\hat{\Omega}_{o}\right), \mu<0
$$

At the bottom of the canopy $\left(x, y, Z_{s}\right)$ a fraction $r_{s}$ is assumed to be reflected back into the canopy by the ground according to the distribution function $\gamma_{s}$.

The equation of transfer for the collided radiation field is

$$
\begin{array}{r}
\hat{\Omega} \bullet \nabla I^{c}(\mathbf{r}, \hat{\Omega})+\sigma(\mathbf{r}, \hat{\Omega}) I^{c}(\mathbf{r}, \hat{\Omega}) \\
=\int_{4 \pi} d \hat{\Omega}^{\prime} \sigma_{s}\left(\mathbf{r}, \hat{\Omega}^{\prime} \rightarrow \hat{\Omega}\right) I^{c}\left(\mathbf{r}, \hat{\Omega}^{\prime}\right)+Q(\mathbf{r}, \hat{\Omega})
\end{array}
$$

where the first collision source $Q$ is

$$
Q(\mathbf{r}, \hat{\Omega})=\int_{4 \pi} d \hat{\Omega}^{\prime} \sigma_{s}\left(\mathbf{r}, \hat{\Omega}^{\prime} \rightarrow \hat{\Omega}\right) I^{o}\left(\mathbf{r}, \hat{\Omega}^{\prime}\right)
$$

The boundary conditions for Equation (4) are vacuum conditions on all sides of the leaf canopy except at the ground interface.

The discrete ordinates method, with some modifications, can be employed to numerically solve equations (2) and (4), subject to their boundary conditions [Myneni et al., 1990; Myneni, 1991]. The collided radiation $I^{c}$ and the uncollided radiation $I^{\circ}$ reflected by the soil into $\hat{\Omega}$ are then used to calculate the canopy bidirectional reflectance factor $R$ and the fraction $f_{a}$ of radiation absorbed by the canopy:

$$
\begin{gathered}
R_{\lambda}(\theta, \phi)=\frac{1}{F_{\lambda}^{\perp}} \int_{x, y} \pi\left[I_{\lambda}^{c}(x, y, 0 ; \theta, \phi)+I_{\lambda}^{o}(x, y, 0 ; \theta, \phi)\right] \\
f_{a, \lambda}=\frac{1}{F_{\lambda}^{\downarrow}} \int_{V} d \mathbf{r}\left[F_{a, \lambda}^{o}(\mathbf{r})+F_{a, \lambda}^{d}(\mathbf{r})+F_{a, \lambda}^{c}(\mathbf{r})\right]
\end{gathered}
$$

where $F_{\lambda}^{\downarrow}$ is the incident radiative flux at a wavelength band centered about $\lambda ; V$ is the volume of the canopy; and $F_{a}^{o}, F_{a}^{d}$, and $F_{a}^{c}$ are the absorbed uncollided sunlight and diffuse, and collided fluxes [Asrar et al., 1992].

This model has been benchmarked extensively with published tables of solutions of some standard radiative transfer problems [Myneni et al., 1988; Ganapol and Myneni, 1992] and validated with measured data [Shultis and Myneni, 1988; Myneni et al., 1988; Asrar et al., 1989; Stewart, 1990; Myneni, 1991; Myneni et al., 1992; Myneni and Asrar, 1993].

\section{Vegetation Submodels}

A numerical evaluation of the interaction cross section requires information on the leaf area density distribution in the stand, leaf normal orientation distribution, and leaf-scattering phase function. In this study, leaf area inside a clump was assumed to be uniformly distributed. The leaf normal orientation was assumed azimuthally symmetric and distributed along the polar angle according to a specific function (planophile, spherical, and so on). Leaf scattering was modeled by 
the bi-Lambertian model [Shultis and Myneni, 1988] where the reflected and transmitted energy was reradiated in a cosine distribution about the leaf normal on each side of the leaf. Leaf hemispherical reflectance and transmittance are obtained from integrating sphere measurements. Specular reflection by leaves was not considered.

The canopy reflectance in the retrosolar direction is enhanced because of the absence of shadows [Marshak, 1989]. This effect is called hot spot. A quantitative description of the hot spot effect requires consideration of leaf spatial distribution and size in the transport formulation leading to correlated probabilities of photon interactions [Myneni et al., 1991]. The resulting equation set is difficult to parameterize and tedious to evaluate. For remote sensing purposes a simple model of the hot spot effect generally suffices. A model for the extinction coefficient that correlates interaction rates between incident and once-scattered photons is used to describe the hot spot effect in our calculations [Marshak, 1989].

\section{Soil Submodel}

Bidirectional reflectance from the soil surface was modeled according to Hapke's formulation [Hapke, 1981]. The soil was assumed to be a half-space, and firstcollision intensity is evaluated analytically, including shadows to model the hot spot effect. Multiple scattering is simplified to a two-stream problem. Hapke's model was successfully applied to bare soil surfaces by Jacquemoud et al. [1992]. The model has four coefficients $\left(b, c, b^{\prime}, c^{\prime}\right)$ of the Legendre polynomial expansion for the particle phase function, a parameter $h$ related to the porosity of the medium, and a single-scattering albedo of the soil particulates $\omega_{s}$ depending on wavelength and soil moisture.

\section{Model Outputs and Numerical Considerations}

To obtain valid simulations, a sensitivity analysis was performed on the parameterization of a vegetation clump. A vegetation stand made of one square clump covering $25 \%$ of the ground was simulated by using different numbers of cells to parameterize the vegetation clump: $(1 \times 1 \times 1)$ cell to $(14 \times 14 \times 14)$ cells, the size of the stand varying proportionally to hold ground cover constant. The results of the simulations are presented for the bidirectional reflectance factors and for the absorption fractions in the red (Figure 2a) and near-infrared channels (Figure $2 \mathrm{~b}$ ). It can be seen that the output of the model becomes stable around a value of four cells in each spatial dimension. So, when possible, the vegetation clumps will be parameterized by $(4 \times 4 \times 4)$ cells at the least.

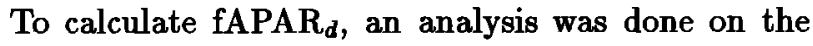
number of integration points. Simulations with a canopy of $25 \%$ of vegetation cover indicate that daily fAPAR calculated with eight values of instantaneous fAPAR spread on half a day (the fAPAR profile is symmetrical around noon) can be considered as a good approximation of the "true" fAPAR . $_{d}$
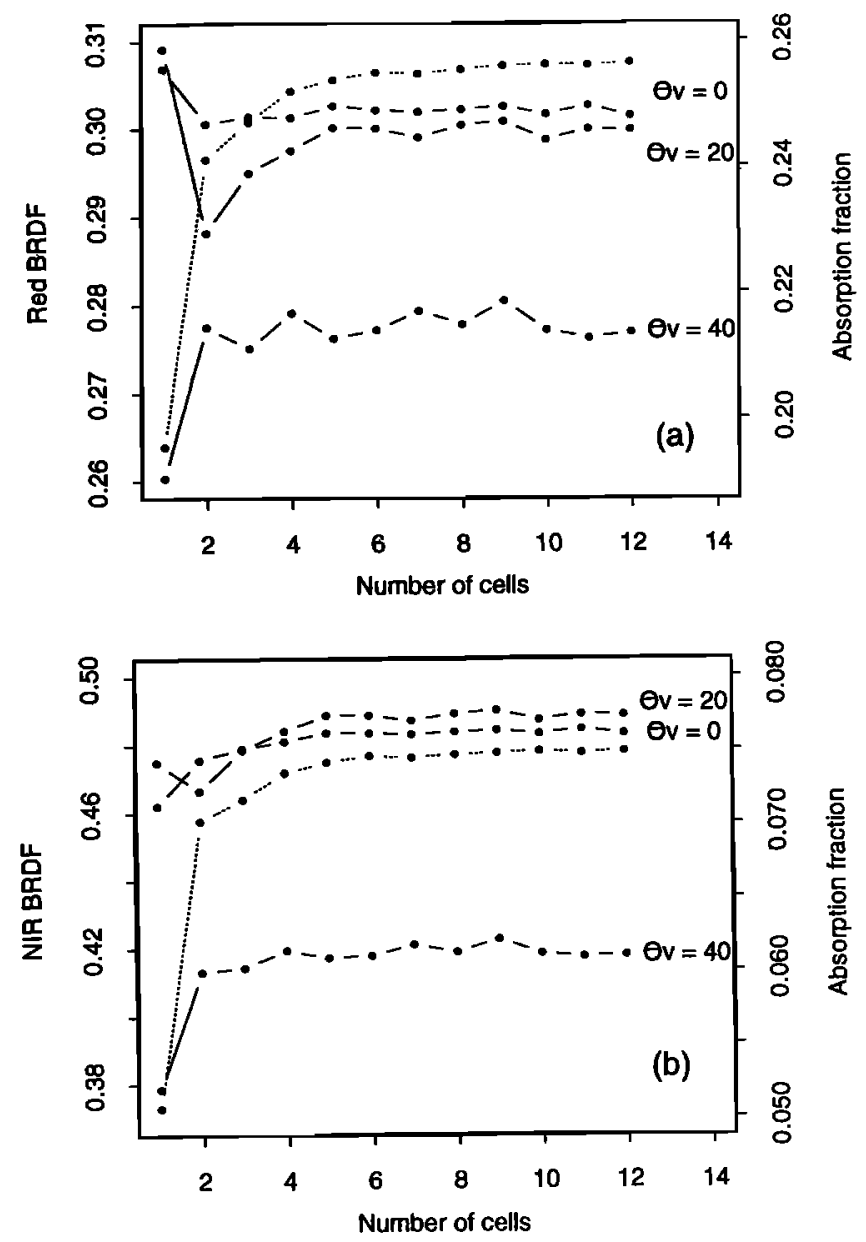

Figure 2. Bidirectional reflectance factors (solid lines) and absorption fractions (dotted lines) in the (a) red and (b) near-infrared channels as a function of the number of cells used to represent the side of a vegetation clump. The simulations were made for three view angles, a solar zenith angle of $30^{\circ}$, an azimuthal difference of $225^{\circ}, 70 \%$ of direct radiation, for a canopy with $25 \%$ ground cover, LAI of 0.5 , and a soil reflectance factor of 0.4 and 0.5 in the red and near-infrared, respectively.

Two vegetation indices were calculated from the red (R) and near-infrared (NIR) reflectances:

The normalized difference vegetation index (NDVI) [Rouse et al., 1974] is the most commonly used index, and many of the historical NOAA series data are available only in this form. Furthermore, for bright soil background likewise in most of the semiarid regions the fAPAR-NDVI relationship has a good linearity [Choudhury, 1987; Goward and Huemmrich, 1992]. The formula is

$$
\text { NDVI }=\frac{\text { NIR }-R}{\text { NIR }+ \text { R }}
$$

The modified soil adjusted vegetation index (MSAVI) [Qi et al., 1994] is part of the new generation of vegetation indices (such as SAVI and TSAVI) which minimize soil influence on canopy spectra by incorporating a soil adjustment factor $L$. The $L$ function is here derived 
by using the product of the NDVI and the weighted difference vegetation index (WDVI):

$$
\begin{aligned}
\text { WDVI } & =\text { NIR }-\gamma \mathrm{R} \\
L & =1-2 \gamma \text { NDVI WDVI } \\
\text { MSAVI } & =\frac{\text { NIR-R }}{\text { NIR }+R+L}(1+L)
\end{aligned}
$$

where $\gamma$ is the slope of the linear relationship between $\mathbf{R}$ and NIR reflectance of bare soil (the "soil line" concept [Baret et al., 1993]).

\section{Parameterization of the Sahelian Vegetation}

The radiative transfer model needs inputs of the structure of vegetation canopies, leaf and soil optical properties, and the Sun-sensor geometry. In this section the magnitude and range of these input variables is discussed. The set of values used in the simulations is given in Table 1.

\section{Millet Crop Canopies}

Some agronomic data of millet were found in the database of the ESPACE network [Forest et al., 1993]. Data from plots in regions with less than $600 \mathrm{~mm} /$ year were extracted. A total of 1316 plots in three countries (Niger, Senegal, and Mali) between 1986 and 1992 were documented with agronomic features. Data processing gave median emergence and harvest dates around day of the year (DOY) 160 and DOY 270, respectively, and five equipopulated classes of crop densities. The range of size (radius and height) of the millet clump and of the leaf area index (LAI) of the canopy have been determined from various field experiments. The leaf inclination distribution function (LIDF) was taken spherical [Prince et al., 1996a]. A value of 4.0 for the hot spot parameter (ratio of clump height to characteristic leaf dimension) was used.

Not all the $\mathbf{4 5 0}$ vegetation models derived from Table 1 are realistic, for instance, clumps of $2.5 \mathrm{~m}$ height and $0.2 \mathrm{LAI}$. To eliminate these unrealistic vegetation models, a test was performed on the porosity of the clumps. The porosity $p$ is defined here as [Bégué, 1992]

$$
p=\exp \left(-K_{c} L(1-\tau)\right)
$$

where $L$ is the leaf area index of the clump (ratio between the area of the element and the area of the horizontal projection of the clump), $\tau$ is the transmittance of the leaves in the PAR region, and $K_{c}$ is the extinction coefficient of the clump, dependent on the radius $r$ and height $h$ of the clump, and expressed for spherical canopies as

$$
K_{c}=0.664-0.590 \exp (-1.239 r / h)
$$

Only these vegetation models with a clump porosity of 0.4 to 0.6 were retained. These values were determined from previous field measurements which showed that the porosity of the millet clump was nearly constant throughout the crop development [Bégué et al., 1991, 1996]. An additional restriction on vegetation cover ( $>5 \%$ ) was made. With these criteria for selection the number of vegetation models was reduced to 67.

Table 1. Values of Vegetation and Sun-View Configuration Input Parameters Used in the Simulations

\begin{tabular}{ll}
\hline \multicolumn{1}{c}{ Parameters } & \multicolumn{1}{c}{ Values } \\
& \multicolumn{1}{c}{ Millet } \\
Density, clumps/ha & $4000-5000-6000-7500-10000$ \\
Radius, m & $0.1-0.2-0.3-0.4-0.5$ \\
Radius/height & $0.8-1.2-2.0$ \\
LAI & $0.2-0.32-0.5-0.8-1.3-2.0$ \\
LIDF & spherical \\
Leaf reflectance & Red $0.140 ;$ NIR $0.450 ;$ PAR 0.130 \\
Leaf transmittance & Red $0.045 ;$ NIR $0.400 ;$ PAR 0.035 \\
& Savanna \\
Herb cover, \% & $0-10-20-30-40-50-60-70-80-90-100$ \\
Wood cover, \% & $0-10-20-30-40$ \\
LAI ${ }_{h}$ & $1.0-2.4$ \\
LAI & $3.5-4.0$ \\
LIDF & uniform \\
Leaf reflectance & Red $0.130 ;$ NIR $0.470 ;$ PAR 0.120 \\
Leaf transmittance & Red $0.040 ;$ NIR $0.370 ;$ PAR 0.035 \\
Solar zenith angle, deg & $10-20-30-40-50-60$ \\
View angle, deg & $0-10-20-30-40-50$ \\
Azimuthal difference, deg & $5-190$ \\
\hline
\end{tabular}

See text for definition of terms 

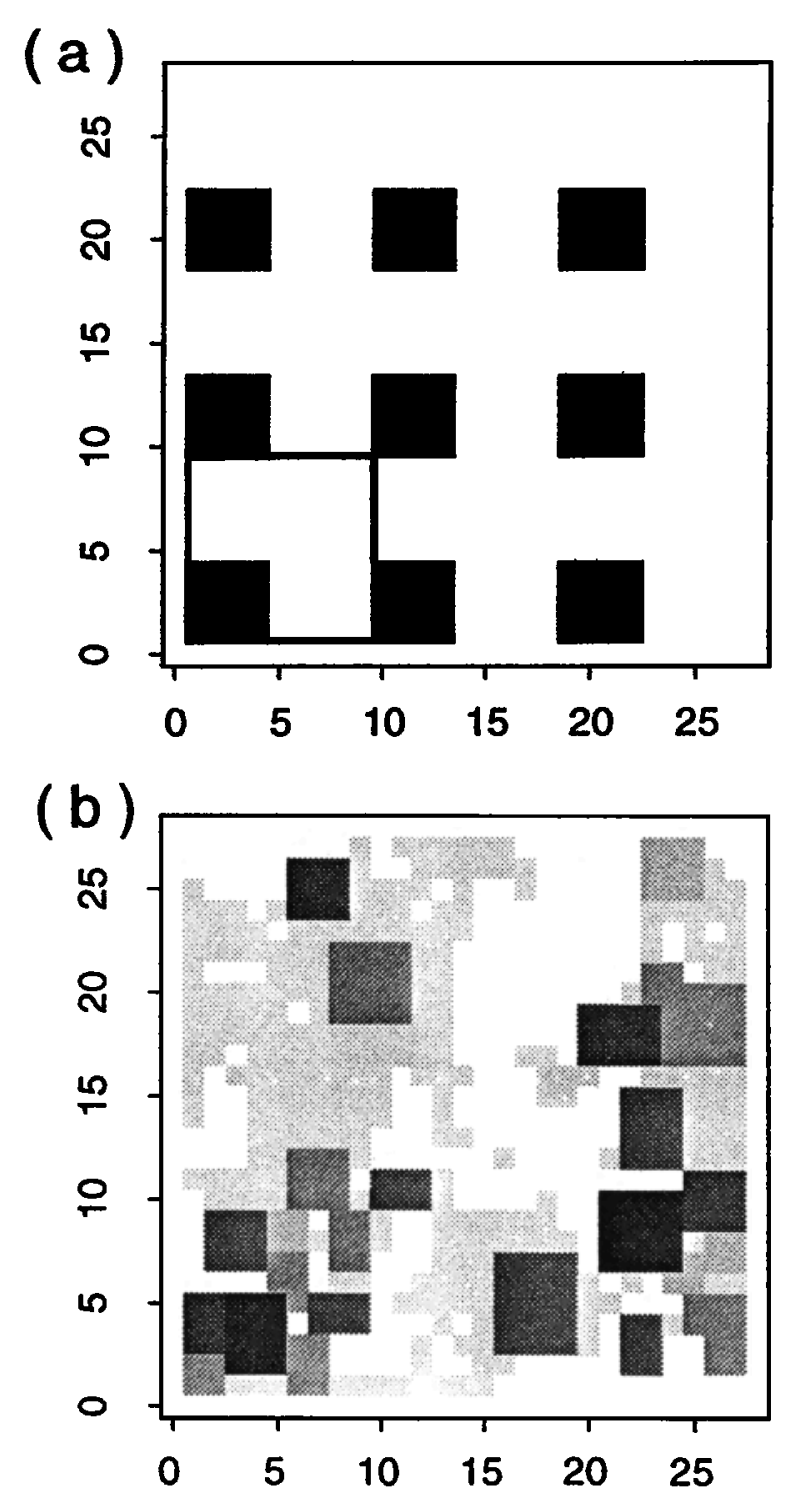

Figure 3. Models of vegetation canopies used in the radiative transfer model. The height of vegetation clumps inside the cells is given in gray scale, from white (no vegetation) to black (maximal height of the stand). (a) A millet crop canopy with a density of 6000 clumps/ha, clump diameter of $0.6 \mathrm{~m}$, and height of $1.5 \mathrm{~m}$ (the actual simulated stand is delineated by a bold line); (b) natural vegetation canopy with an herb layer cover of $50 \%$, a woody layer cover of $30 \%$, and a maximum shrub height of about $4 \mathrm{~m}$ ( 6 cells).

The cross section of a clump was assumed to be a square, with an area of $4 r^{2}$ represented by $16(4 \times 4)$ grid units. The basic stand area, depending on density $d$, is equal to $10000 / d\left(\mathrm{~m}^{2}\right)$ and is represented by a square grid of $4 \sqrt{A_{s}} / d$ units on a side. The simulated stand is representative of the actual vegetation canopy by lateral replication of this basic stand (Figure 3a). A complete simulation of a millet canopy (red and nearinfrared reflectances and $\mathrm{fAPAR}_{d}$ ) requires an average of two CPU hours on a Sparcstation-LX.

\section{Natural Sahelian Vegetation}

An interesting compilation of the natural vegetation in the Sahel is given by Le Houérou [1989]. Le Houérou divides the Sahel into three zones: the Saharo-Sahelian zone (100-200 mm), the Sahelian zone $(200-400 \mathrm{~mm})$, and the Soudano-Sahelian zone $(400-600 \mathrm{~mm})$. For each of these zones he gives a description of the herb and woody layers in terms of fraction of covered soil, height of the layer, species composition, and biomass. The relevant variables used in this study are summarized in Tables 2 and 3. This information was complemented with specific leaf area obtained from measurements on various Sahelian species. These data then permitted evaluation of LAI of the vegetation canopy layers.

The leaf inclination distribution function (LIDF) was measured as uniform on the Guiera senegalensis shrubs, planophile for the forb species and erectophile for the herb species [Prince et al., 1996a]. Because the model accepts only one value for the whole stand, the uniform distribution was used. Likewise the model accepts a unique value for the reflectance and transmittance properties of the phytoelements, and therefore woody components have not been considered in these simulations. A value of 8.0 for the hot spot parameter was used.

A total of 220 vegetation models were simulated to represent the range of selected model variables (Table 1). As in the case of millet, further selection was made to reduce the size of the problem. According to $H$. N. Le Houérou (personal communication, 1994), shrub leaves grow much earlier than the herb layer. This finding was verified in the HAPEX-Sahel field campaign, which showed that the grass layer only began to grow when the woody layer reached its biomass maximum [Prince et al., 1996b]. Thus only two scenarios of LAI have been kept, one corresponding to a savanna of low productivity (LAI of 1.0 and 3.5 for the grass patches and the shrub, respectively) and the other corresponding to a savanna with high productivity (2.4 and 4.0, respectively). This selection reduced the number of vegetation models to 110 .

In the vegetation model the location of the shrubs was determined randomly. The location of the herb patches was preferentially placed close to the shrub as observed in the field. An example of a savanna stand is given in Figure $3 \mathrm{~b}$. The minimal size of the grid unit was imposed by the height of the grass layer $(0.6 \mathrm{~m})$. The basic stand area was $27 \times 27$ grid units which corresponded to a stand of $262 \mathrm{~m}^{2}$. This size was a compromise between a good representation of the heterogeneity of the natural vegetation and a reasonable CPU time. A complete simulation of a natural vegetation canopy (red, near-infrared reflectances and fAPAR $_{d}$ ) required on an average about 5 CPU hours on a Sparcstation-LX.

\section{Leaf and Soil Optics}

The optical properties of a large variety of species leaves were measured during the HAPEX-Sahel experiment by using the Spectron SE590 spectroradiometer 
Table 2. Ranges of Architecture Parameters and Biomass Production of the Woody Layer in Sahelian Savanna

\begin{tabular}{|c|c|c|c|c|c|c|c|}
\hline & $\begin{array}{c}\text { Density } \\
\text { shrubs/ha }\end{array}$ & $\begin{array}{c}\text { Cover }^{a} \\
\%\end{array}$ & $\begin{array}{c}\text { Area } \\
\mathbf{m}^{2} / \mathbf{s h r u b}\end{array}$ & $\begin{array}{c}\text { Diameter } \\
\text { m }\end{array}$ & $\begin{array}{l}\text { Leaves prod. }{ }^{b} \\
\text { g/shrub/year }\end{array}$ & $\begin{array}{c}\mathrm{LAI}_{t}^{c} \\
\text { of a shrub }\end{array}$ & $\begin{array}{c}\text { Height } \\
\text { m }\end{array}$ \\
\hline $\begin{array}{l}\text { Saharo- } \\
\text { Sahelian }\end{array}$ & $\begin{array}{r}0 \\
200\end{array}$ & $\begin{array}{r}0 \\
10\end{array}$ & $\cdots_{5.0}$ & $\begin{array}{l}\cdots \\
2.50\end{array}$ & 1500 & 4.8 & $0.5-2.0$ \\
\hline Sahel & $\begin{array}{r}0 \\
500\end{array}$ & $\begin{array}{r}0 \\
20\end{array}$ & $\cdots_{4.0}$ & $\begin{array}{l}\cdots \\
2.25\end{array}$ & 1200 & 4.8 & $0.5-3.0$ \\
\hline $\begin{array}{l}\text { Sudano- } \\
\text { Sahelian }\end{array}$ & $\begin{array}{r}500 \\
1500\end{array}$ & $\begin{array}{l}20 \\
35\end{array}$ & $\begin{array}{l}4.0 \\
2.3\end{array}$ & $\begin{array}{l}2.25 \\
1.72\end{array}$ & 500 & 2.0 & $0.5-3.0$ \\
\hline
\end{tabular}

Adapted from Le Houérou [1989]. See text for definition of terms.

${ }^{a}$ Sum of the vertical projection of the crown of the shrub divided by the total area.

${ }^{b}$ Twice the value of the browse production [Le Houérou 1989].

${ }^{c}$ Calculated with a leaf specific area of $160 \mathrm{~cm}^{2} \mathrm{~g}^{-1}$ [Poupon 1979].

with the Licor integrating sphere [Hanan and Prince, 1996]. In this study, only the green leaves (young, mature and old) of millet, Guiera senegalensis shrubs and Andropogon and Chrozophora herb species were considered. Integration of these data over the photosynthetically active radiation (PAR) range, and NOAA-AVHRR red and near-infrared bands was performed.

In the same way a large variety of surface soil signatures was collected during HAPEX-Sahel with a Spectron SE590 spectroradiometer using a $4^{\circ}$ field of view mounted $50 \mathrm{~cm}$ above the soil under clear sky conditions. Three soils likely to be found in the Sahelian zone have been selected and correspond to two sandy soils and a soil covered with litter [Huete and van Leeuwen, 1996]. Jacquemoud et al.'s [1992] soil model was inverted on the measured bidirectional reflectances to obtain the soil model parameters (J. Privette, personal communication, 1993) used in the 3-D model. Simulated soil reflectance factors were used to calculate the slopes of the soil lines (equation (9)) and a mean soil NDVI (NDVI $)_{s}$ ) and soil MSAVI (MSAVI $)$. Values of the parameters, slopes, and soil VI are given in Table 4.

\section{Sun and Sensor Geometry}

The Sun and sensor geometry used in the simulations was taken to be representative of the whole NOAA series. The extreme view angles of the AVHRR sensors have not changed since the beginning of the series and are $\pm 55^{\circ}$. These view angles correspond at the surface to $\pm 69^{\circ}$. In this study the maximum surface view angles are $\pm 50^{\circ}$, corresponding to sensor view angles of $\pm 42^{\circ}$. Beyond these view angles, radiometric data are rarely processed because of pixel extreme deformation and atmospheric contamination. Between 1981 and 1992, which correspond to NOAA satellites 7,9 , and 11, the equatorial crossing time of the satellites varied between 1340 LT and 1640 LT because of the launch time of the satellite and its temporal drift [Price, 1991]. These times correspond at the Sahel latitude $\left(13^{\circ} \mathrm{N}\right.$ to $\left.17^{\circ} \mathrm{N}\right)$ to a range of solar angles between $10^{\circ}$ and $60^{\circ}$ during the rainy season (July to September). The azimuthal difference between the Sun and the sensor was calculated for the entire series (Figure 4), and a median value corresponding to the backscattering and the forwardscattering configurations is given.

Table 3. Ranges of Architecture Parameters and Biomass Production of the Herb Layer in Sahelian Savanna

\begin{tabular}{lcccccc}
\hline & & & \multicolumn{2}{c}{ Herb patches } & \multicolumn{2}{c}{ Total } \\
\cline { 3 - 7 } & $\begin{array}{c}\text { Herb cover } \\
\%\end{array}$ & $\begin{array}{c}\text { Herb Height } \\
\mathbf{m}\end{array}$ & $\begin{array}{c}\text { Production } \\
\mathrm{g} / \mathrm{m}^{2} / \text { year }\end{array}$ & $\mathrm{LAI}^{a}$ & $\begin{array}{c}\text { Production } \\
\mathrm{g} / \mathrm{m}^{2} / \text { year }\end{array}$ & $\mathrm{LAI}^{b}$ \\
\hline Saharo- & 5 & $0.40-0.80$ & 15 & 0.12 & 300 & 2.40 \\
Sahelian & 20 & & 60 & 0.48 & 300 & 2.40 \\
Sahel & 20 & $0.40-2.00$ & 50 & 0.40 & 250 & 2.00 \\
& 80 & & 250 & 2.00 & 312 & 2.50 \\
Sudano- & 30 & $0.64-2.40$ & 80 & 0.64 & 267 & 2.14 \\
Sahelian & 100 & & 300 & 2.40 & 300 & 2.40 \\
\hline
\end{tabular}

Adapted from Le Houérou [1989]. See text for definition of terms.

${ }^{a}$ Calculated with a leaf specific area of $80 \mathrm{~cm}^{2} \mathrm{~g}^{-1}$ [Prince et al., 1996a].

${ }^{b} \mathrm{LAI}$ of the herb patches. 
Table 4. Soil Parameters Derived From Jacquemoud's Model, Slope of the Soil Line and Vegetation Indices of the Soils

\begin{tabular}{lrrr}
\hline & Sand 1 & Sand 2 & Litter \\
\hline$\omega_{s}$ & & & \\
Red & 0.8875 & 0.8386 & 0.5312 \\
NIR & 0.9504 & 0.9266 & 0.7230 \\
PAR & 0.7227 & 0.6634 & 0.3826 \\
$h$ & 0.1681 & 0.0001 & 2.0000 \\
$b$ & 0.2743 & -0.1261 & 0.3636 \\
$c$ & -0.0727 & 0.3924 & 0.2305 \\
$b^{\prime}$ & -0.5289 & 0.4385 & -0.1274 \\
$c^{\prime}$ & 0.3491 & -0.1669 & 0.3915 \\
& & & \\
Slope & 1.000 & 1.000 & 1.370 \\
NDVI & 0.149 & 0.173 & 0.220 \\
MSAVI & 0.149 & 0.161 & 0.172 \\
\hline
\end{tabular}

See text for explanation of Jacquemoud's model and definition of terms.

The fraction of diffuse radiation $f_{D}$ through the day was described by the following function established on Niger data:

$$
\begin{aligned}
f_{D} & =\frac{a}{a+\cos \left(\theta_{s}\right)} \\
a & =-0.026+0.966 * \tau_{550}
\end{aligned}
$$

where $\tau_{550}$ is the optical depth at $550 \mathrm{~nm}$ and $\theta_{s}$ is the solar zenith angle.

In this study an optical depth of 0.2 was assumed. The change in fraction of diffuse radiation from one spectral band to the other is made through the use of coefficients established from atmospheric radiative transfer modeling (D. Tanré, personal communication, 1994).

\section{Relative azimuth angle}

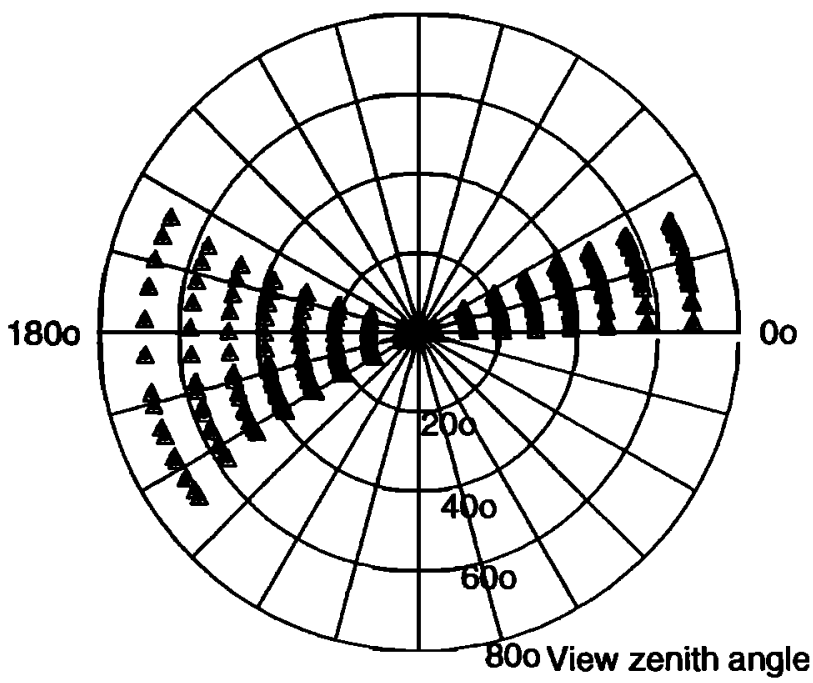

Figure 4. Polar representation of the azimuthal difference between the Sun and AVHRR sensor (NOAA 7, 9 and 11), calculated over the Sahel (from latitude $13^{\circ}$ to $17^{\circ}$ north) during the rainy season (July to September).

\section{Results}

\section{Variability of the fAPAR-VI Relationship}

Millet crop canopies. Figure 5 shows the calculated fAPAR fo $_{d}$ of thillet data set against the vegetation indices. The scatter is very important. It is higher when fAPAR $_{d}$ is plotted against NDVI (Figure 5a) than against MSAVI (Figure 5b), especially at low values of fAPAR ${ }_{d}$, where the soil effects are minimized by MSAVI. Despite an obvious deviation from linearity, no attempt was made to fit nonlinear relationships for operational reasons (to obtain scale invariant relations). We rather chose to fit linear relationships and quantify the resulting error on the fAPAR estimation. The coefficients of regression lines, fitted between fAPAR $_{d}$ and the VIs for each of the simulated soil types and the whole set of points, are given in Table 5.

When atmospheric effects are corrected and the background effect is minimized through a combination of
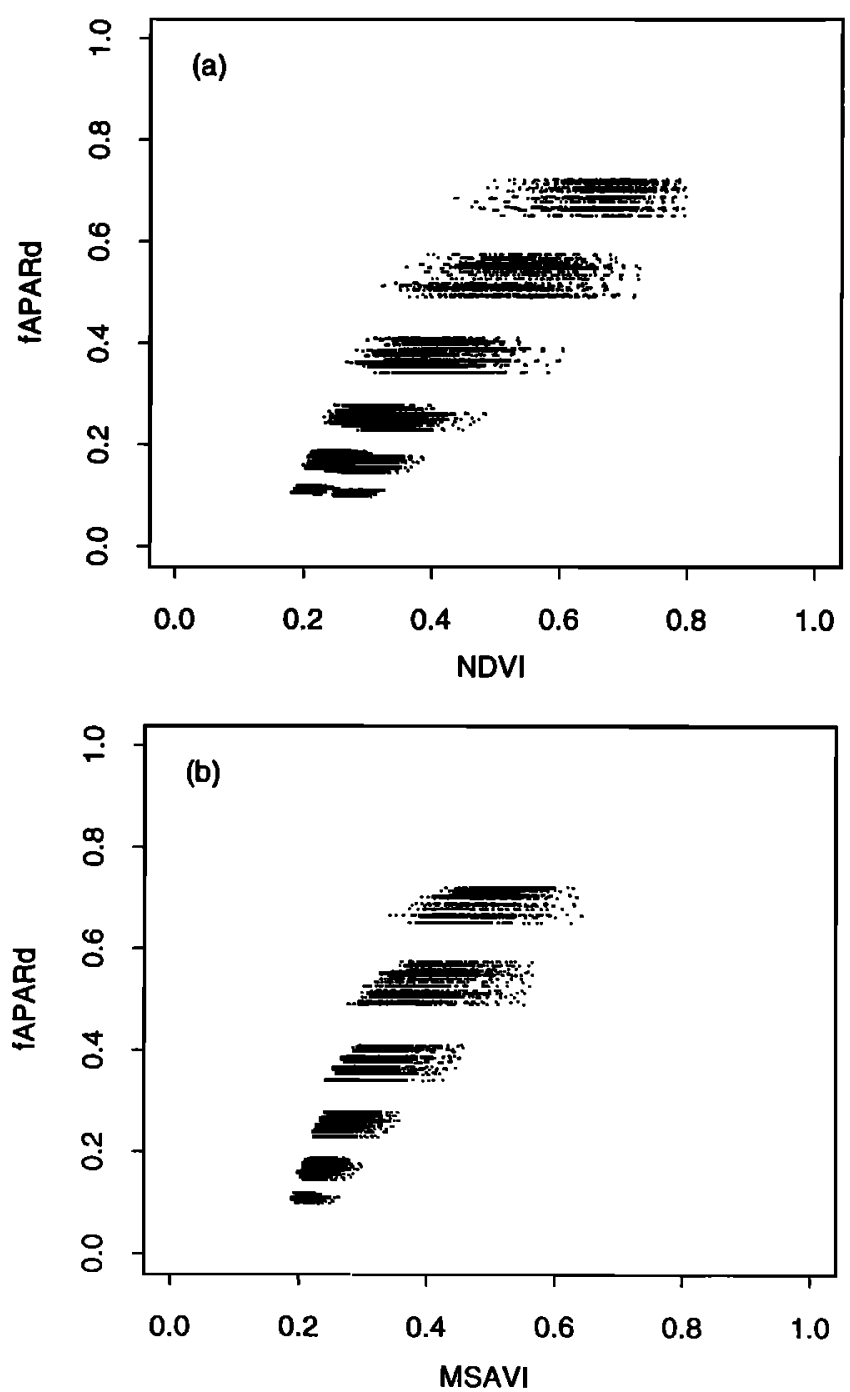

Figure 5. Daily fAPAR plotted versus (a) NDVI and (b) MSAVI for millet canopies (all the simulation points are considered). 
Table 5. Slopes, Intercepts, Coefficients of Correlation and root mean square errors of the Linear Regressions fAPAR $d=a$ VI $+b$, Calculated With NDVI or MSAVI for Sahelian Canopies

\begin{tabular}{|c|c|c|c|c|c|}
\hline & Sand 1 & Sand 2 & Litter & All soils & No intercept ${ }^{a}$ \\
\hline \multicolumn{6}{|c|}{ Millet } \\
\hline Slope $a$ & $\begin{array}{l}1.171 \\
1.712\end{array}$ & $\begin{array}{l}1.209 \\
1.823\end{array}$ & $\begin{array}{l}1.243 \\
1.817\end{array}$ & $\begin{array}{l}1.172 \\
1.775\end{array}$ & $\begin{array}{r}1.501 \\
2.145\end{array}$ \\
\hline Intercept $b$ & $\begin{array}{l}-0.069 \\
-0.182\end{array}$ & $\begin{array}{l}-0.113 \\
-0.218\end{array}$ & $\begin{array}{l}-0.203 \\
-0.209\end{array}$ & $\begin{array}{l}-0.198 \\
-0.105\end{array}$ & $\begin{array}{l}\cdots \\
\ldots\end{array}$ \\
\hline$r$ & $\begin{array}{l}0.947 \\
0.946\end{array}$ & $\begin{array}{l}0.950 \\
0.941\end{array}$ & $\begin{array}{l}0.928 \\
0.906\end{array}$ & $\begin{array}{l}0.925 \\
0.991\end{array}$ & $\begin{array}{l}0.942 \\
0.924\end{array}$ \\
\hline RMSE & $\begin{array}{l}0.062 \\
0.062\end{array}$ & $\begin{array}{l}0.059 \\
0.065\end{array}$ & $\begin{array}{l}0.070 \\
0.080\end{array}$ & $\begin{array}{l}0.072 \\
0.070\end{array}$ & $\begin{array}{l}0.082 \\
0.087\end{array}$ \\
\hline \multicolumn{6}{|c|}{ Savanna } \\
\hline Slope $a$ & $\begin{array}{l}1.165 \\
1.639\end{array}$ & $\begin{array}{l}1.235 \\
1.758\end{array}$ & $\begin{array}{l}1.327 \\
1.794\end{array}$ & $\begin{array}{l}1.189 \\
1.723\end{array}$ & $\begin{array}{l}1.710 \\
2.213\end{array}$ \\
\hline Intercept $b$ & $\begin{array}{c}0.021 \\
-0.105\end{array}$ & $\begin{array}{l}-0.041 \\
-0.159\end{array}$ & $\begin{array}{l}-0.142 \\
-0.160\end{array}$ & $\begin{array}{l}-0.026 \\
-0.137\end{array}$ & $\begin{array}{l}\cdots \\
\cdots\end{array}$ \\
\hline$r$ & $\begin{array}{l}0.933 \\
0.970\end{array}$ & $\begin{array}{l}0.940 \\
0.979\end{array}$ & $\begin{array}{l}0.925 \\
0.965\end{array}$ & $\begin{array}{l}0.909 \\
0.968\end{array}$ & $\begin{array}{l}0.931 \\
0.961\end{array}$ \\
\hline RMSE & $\begin{array}{l}0.058 \\
0.099\end{array}$ & $\begin{array}{l}0.055 \\
0.097\end{array}$ & $\begin{array}{l}0.062 \\
0.049\end{array}$ & $\begin{array}{l}0.068 \\
0.040\end{array}$ & $\begin{array}{l}0.086 \\
0.068\end{array}$ \\
\hline
\end{tabular}

Numbers in italic are MSAVI. See text for definition of terms.

${ }^{a}$ Calculated with (VI-VIs) instead of (VI).

spectral channels, the scatter of the fAPAR $_{d^{-}}$VI relationship is mainly due to the anisotropy of the surface. This anisotropy depends on the structure of the vegetation canopy and is expressed by differential sensitivity of the canopy reflectance to the Sun-view geometric config- uration. To illustrate the effect of the surface anisotropy on the fAPAR $_{d}$-VI relationship in the case of a millet canopy, a series of increasingly restrictive sets of simulations were individually analyzed. Figure $6 \mathrm{a}$ shows one soil, Figure $6 \mathrm{~b}$ shows one soil and one vegetation struc-
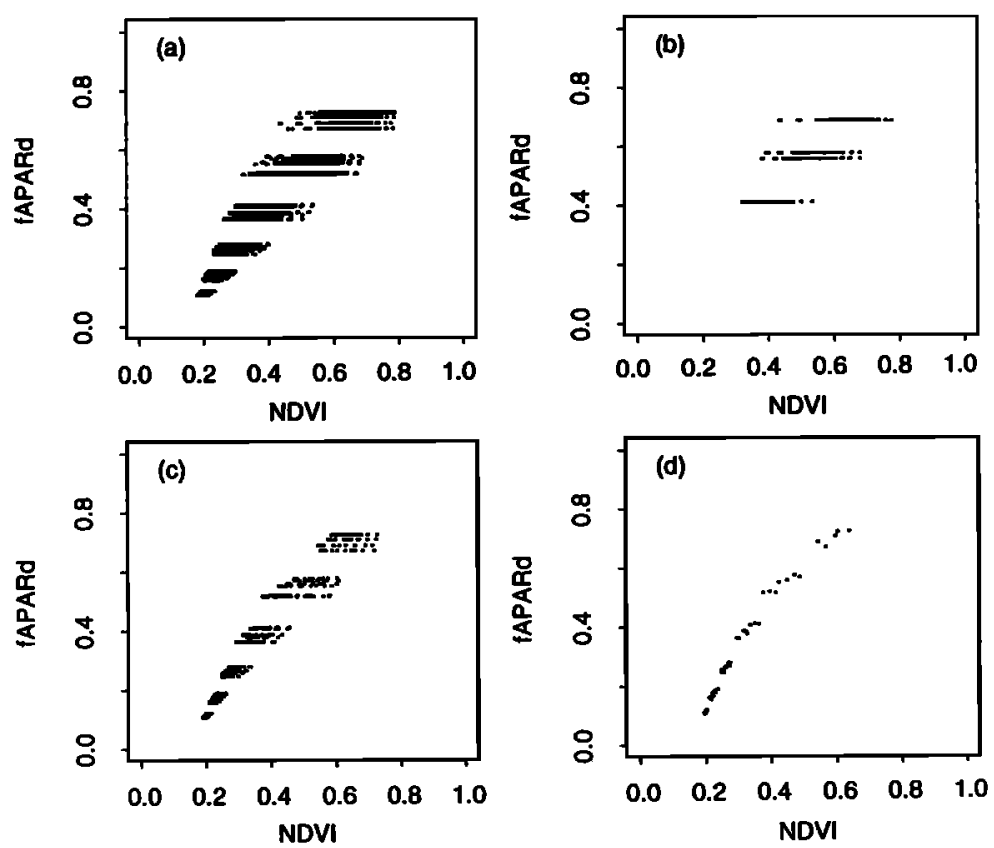

Figure 6. Daily fAPAR-NDVI relationships for millet canopies over a bright sandy soil: (a) All cases, (b) one canopy structure, (c) one solar zenith angle $\left(30^{\circ}\right)$, and (d) one Sun-view geometry (solar angle equals $30^{\circ}$ and nadir viewing). 
ture (one clump density and LAI $>1$ ), Figure $6 \mathrm{c}$ shows one soil, one structure, and one solar angle, and Figure $6 \mathrm{~d}$ shows one soil, one structure, and one Sun-view angle. When only one soil is considered (Figure 6a), the variability is significantly decreased at low fAPAR values as expected. When a unique structure is considered (Figure 6b), the scatter is still very high. This finding shows that the variability of the relationship is mainly due to the Sun and view angles of the image acquisition (Figures 6c and 6d). Since these angles are known in the case of NOAA-AVHRR acquisition, this information was used in the following analysis to decrease the variability of the fAPAR-VI relationship.

Natural Sahelian vegetation. Figure 7 shows the calculated fAPAR $_{d}$ of the whole natural vegetation data set against NDVI (Figure 7a) and MSAVI (Figure $7 \mathrm{~b}$ ). The scatter of the relationship with NDVI is high, while it is much less with MSAVI. Furthermore, the assumed linearity of the relationship seems to be more realistic in this case than in the case of millet canopies. The coefficients of the regression lines, fitted
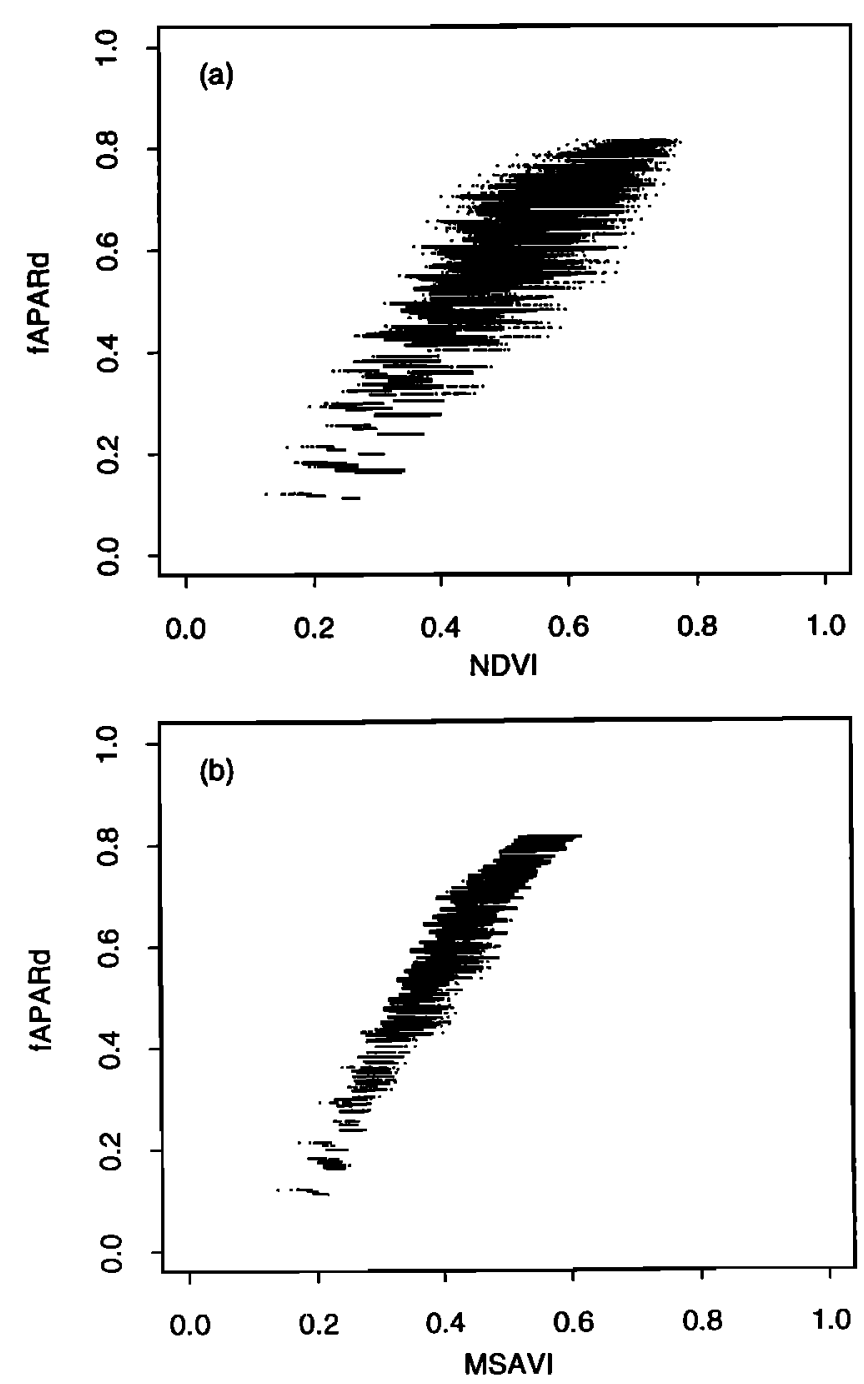

Figure 7. Daily fAPAR plotted versus (a) NDVI and (b) MSAVI for natural vegetation (all the simulation points are considered). between fAPAR $_{d}$ and the Vls for each simulated soil type and the whole set of points, are given for information in Table 5.

When we investigate the cause of the scatter (Figure 8), as was done previously with the millet data set, the conclusions are a little different. Contrary to the millet simulations, the Sun and view angles do not explain the majority of the variance (Figures $8 \mathrm{c}$ and $8 \mathrm{~d}$ ). The greater variability here must be related to the variety of simulated canopy structures, which have their own anisotropy.

\section{Algorithms for Estimating APAR $_{d}$}

In the definition of algorithms for calculating fAPAR $\mathrm{f}_{d}$ from vegetation indices, millet and natural vegetation canopies have been treated separately because they can address different problems. In effect, from a geographical point of view, savanna (natural or fallow) is the predominant vegetation type in the Sahel. But from an economical point of view, millet is the main crop resource for the population of the Sahel.

Millet crop canopies. For each Sun-view angle pair in the back and forward direction, regression lines were fitted to the results of all vegetation structure and soil simulations:

$$
\mathrm{fAPAR}_{d}=a\left(\theta_{s}, \theta_{v}, \phi\right) \mathrm{VI}+b\left(\theta_{s}, \theta_{v}, \phi\right)
$$

where $\theta_{s}$ and $\theta_{v}$ are the solar and view zenith angles, respectively, and $\phi$ is the difference between the solar and view azimuth angles.

The slope $a$ of the relationship established with NDVI varies with the Sun-view geometric configuration, with maxima corresponding to the hot spot configurations (Figure 9a). With MSAVI the values of the slope are maximal at nadir and symmetrical in the back and forward directions, an intrinsic property of this vegetation index. In both cases the slope of the relationship is very sensitive to the geometry of data acquisition, with a range between 1.0 and 1.9 for the NDVI and between 1.4 and 2.7 for the MSAVI. The intercept of the relationship is also sensitive to the geometry for NDVI (between -0.15 and -0.26 ; Figure $9 \mathrm{~b}$ ) and MSAVI (between -0.25 and -0.38 ).

To quantify the quality of the fAPAR $_{d}$-VI relationship, the root mean square error of each linear regression was calculated. The $\mathrm{fAPAR}_{d}$ RMSE isolines, plotted as a function of the Sun and view angles (Figure 9c for NDVI), are an indicator of the optimal Sun-view configuration to estimate $\mathrm{fAPAR}_{d}$. The error is maximum for low-view and solar zenith angles (about 0.06 for NDVI and 0.04 for MSAVI) and minimum for highview and Sun angles (less than 0.04 for NDVI and 0.02 for MSAVI). In addition, the errors are not symmetrical around nadir viewing and are larger in the hot spot direction. This conclusion is totally dependent on the type of vegetation canopy and the background properties and is valid for the fAPAR ${ }_{d}$ retrieval. It cannot be generalized for other purposes or vegetation covers. 

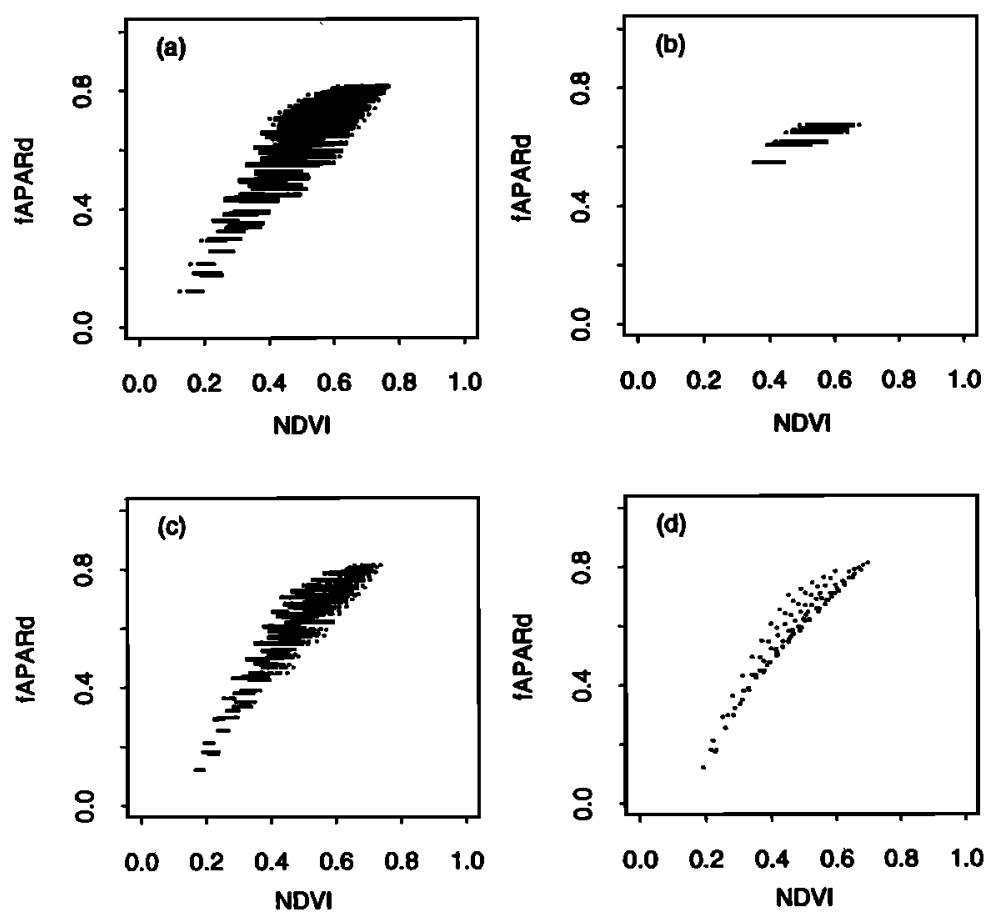

Figure 8. Daily fAPAR-NDVI relationships for natural vegetation over a bright sandy soil: (a) all cases, (b) one canopy structure, (c) one solar zenith angle $\left(30^{\circ}\right)$, and (d) one Sun-view geometry (solar angle equals $30^{\circ}$ and nadir viewing).

For simplification, a one-parameter model for estimating fAPAR $_{d}$ from VI is derived on the assumption that $\mathrm{fAPAR}_{d}$ equals zero when the VI equals the VI of the bare soil $\left(\mathrm{VI}_{s}\right)$ :

$$
\mathrm{fAPAR}_{d}=a\left(\theta_{s}, \theta_{v}, \phi\right)\left(\mathrm{VI}-\mathrm{VI}_{s}\right)
$$

For MSAVI the values of the slope $a$ in the back and forward direction have been averaged as they were symmetrical around nadir viewing (Figure 10a). The range of slopes is larger than that when the two linear regression coefficients were adjusted (between 1.0 and 2.4 for NDVI and between 1.5 and 3.0 for MSAVI). The RMSE are slightly higher, about 0.02 (Figure 10b), and distributed differently.

Natural Sahelian vegetation. The procedure described above was applied to the natural vegetation data set. The fitted coefficients $a$ and $b$ of equation (13) are presented in Figures 11a and 11b. Here again the slope of the NDVI relationship depends on the geometry of the data acquisition but is much less sensitive than that for millet (slope between 1.1 and 1.5). The intercept is almost invariant of the geometry of data acquisition. The coefficients of the linear regression with MSAVI are only slightly dependent on the geometry (slope between 1.6 and 1.9).

For NDVI the RMSE is almost independent of the geometric configuration and is close to 0.06 (Figure 11c). For MSAVI the errors are maximum at low-view and Sun angles (about 0.05), but contrary to the results for millet, the error is only slightly sensitive to the view angle.
The one-parameter model (equation (14)) was fitted to the natural vegetation data. The values of the slope $a$ ranged between 1.5 and 2.15 for the NDVI. For MSAVI (Figure 12a) it is interesting to note that the slope $a$ is almost invariant of the Sun-sensor geometric configuration and is around 2.2. For both vegetation indices the error on fAPAR $_{d}$ is between 0.06 and 0.08 (Figure 12b).

\section{An Example Application}

To test the methodology, two different fAPAR $_{d}$-NDVI algorithms were applied to two sites within the HAPEXSahel $1^{\circ} \times 1^{\circ}$ site. The first site $\left(2^{\circ} 33^{\prime} \mathrm{E} ; 1^{\circ} 39^{\prime} \mathrm{N}\right)$ is mainly composed of millet (about $80 \%$ ), while the second site $\left(2^{\circ} 39^{\prime} \mathrm{E} ; 13^{\circ} 06^{\prime} \mathrm{N}\right)$ is composed of savanna (between $50 \%$ and $100 \%$ ), according to d'Herbès et al. [1992]. The 1-km-resolution AVHRR data were extracted from atmospherically corrected 1992 NOAA LAC time series [Kerr et al., 1993]. From clear images the red and near-infrared channel data were used to calculate NDVI and MSAVI time profiles of the two sites, and the Sun and view angles corresponding to the data acquisition were identified (Figures 13a and 14a). Two extreme algorithms were applied on these data (Table 5): (1) the global relationship between fAPARd and NDVI, established for each canopy type from all of our simulations, and (2) the relationship between fAPAR $_{d}$ and (MSAVI-MSAVI ${ }_{s}$ ), whose coefficient is a function of the geometry of the acquisition. In the latter case the slope of the soil line and MSAVI, was calculated from the first points in the time series (before the rains started). 
MILLET : fAPARd $=a \mathbf{N D V I}+b$
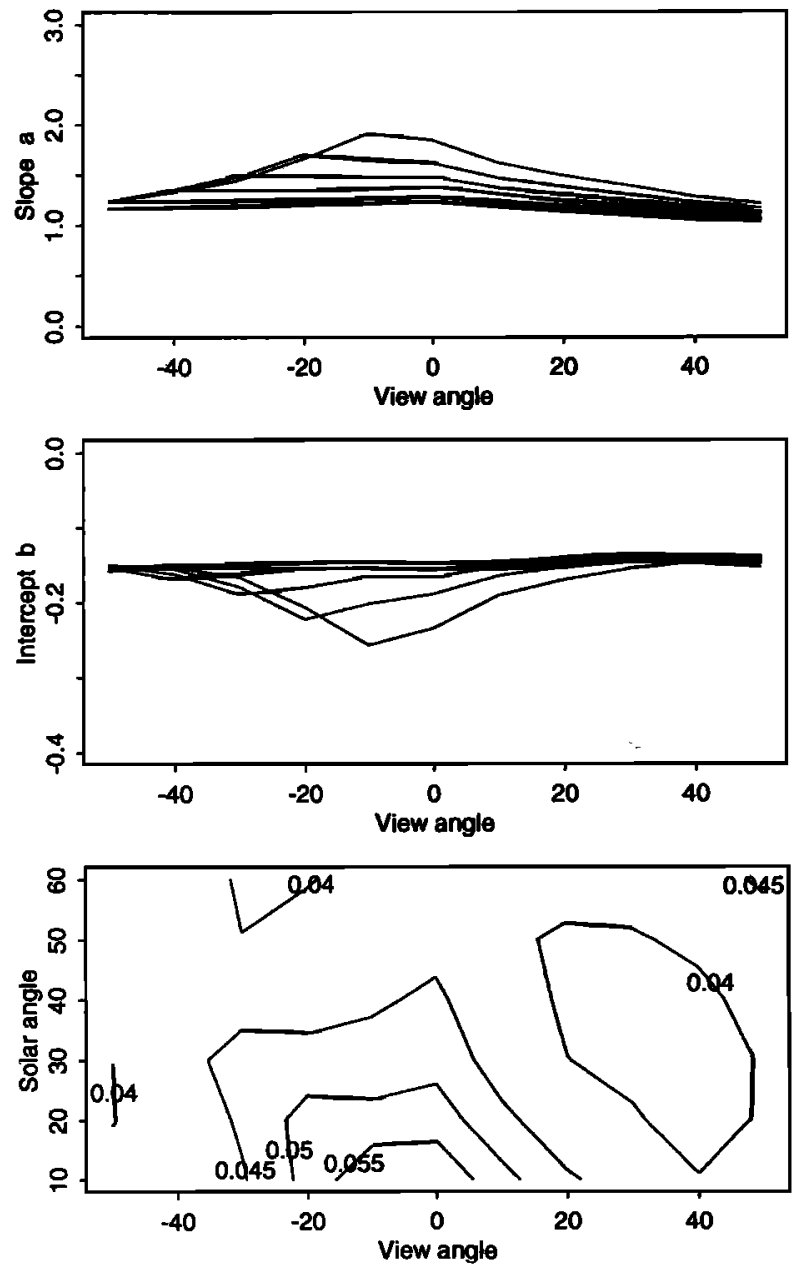

(c)

Figure 9. Variations of the (a) slope $a$ and (b) intercept $b$ as a function of Sun-sensor geometry, and (c) the corresponding error isolines. In Figure 9a the curves from top to bottom correspond to an increasing solar zenith angle (from $10^{\circ}$ to $60^{\circ}, 10^{\circ}$ interval). In Figure 9b the curves from top to bottom correspond to a decreasing solar zenith angle (from $60^{\circ}$ to $10^{\circ}, 10^{\circ}$ interval).

The simulation results are presented in Figures 13b and $14 \mathrm{~b}$ for millet and natural vegetation, respectively. Globally, the shape of the profiles is different depending on the algorithm used. When the global relationship is used, fAPAR ${ }_{d}$ estimation is poor at the beginning of the season because of local soil effects. This result is particularly pronounced for the natural vegetation, which shows $12 \%$ fAPAR before the vegetation grows. In this case, no angular correction was applied. The fAPAR profile calculated with the second algorithm has a larger amplitude compared to the $\mathrm{fAPAR}_{d}$ calculated with the global relationship.

For natural vegetation it is interesting to note that fAPAR $_{d}$ calculated with the second algorithm decreases suddenly around DOY 260 . This decrease corresponds to the end of the rains and to a drop in the soil water content measured in the fields [Wallace et al., 1994].

For millet, vegetation indices and fAPAR $_{d}$ calculated with the global relationship exhibit a peak in vegeta- tion around DOY 260, while this peak is replaced by a plateau when the second algorithm is used. In fact, during this period (between DOY 240 and 260) the zenith angle of the acquisition increased from $30^{\circ}$ to $50^{\circ}$, leading to an artificial increase in the vegetation indices. Therefore the use of an algorithm that takes into account the geometrical effects of the acquisition corrects this artefact. The result is a smoother profile for the fAPAR $_{d}$ seasonal evolution that is closer to the ground observations [Bégué et al., 1996].

At the end of the growing season, both algorithms give high $\mathrm{fAPAR}_{d}$ values, while in fact, $\mathrm{fAPAR}_{d}$ should be close to zero. This discrepancy is due to the fact that the background is no longer bare soil, but soil covered with senescent vegetation (therefore a higher VI).

A successful application of these relations to NOAA imagery is given by Ouaidrari [1994]. Taking into account the geometry of data acquisition decreased the

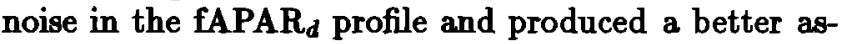
sessment of the primary production of millet.

\section{Discussion and Conclusion}

Millet crop and natural vegetation canopies are radiometrically different. Millet crop canopies are highly anisotropic because of their architecture, which is composed of a high density of vertical protrusions. This architecture induces a higher sensitivity in the reflectance to the geometry of acquisition, even though there is very little sensitivity to the structure itself in the case of our simulations (performed as realistically as possible). In contrast, natural vegetation is not very anisotropic be-

\section{MILLET : fAPARd = a (MSAVI-MSAVIs)}

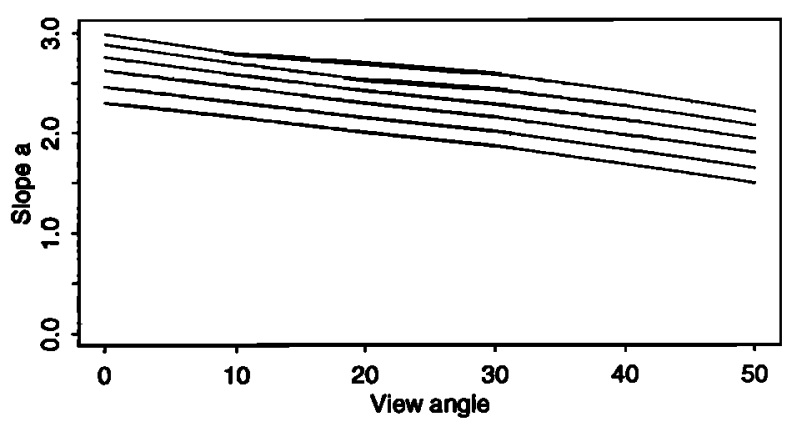

(a)

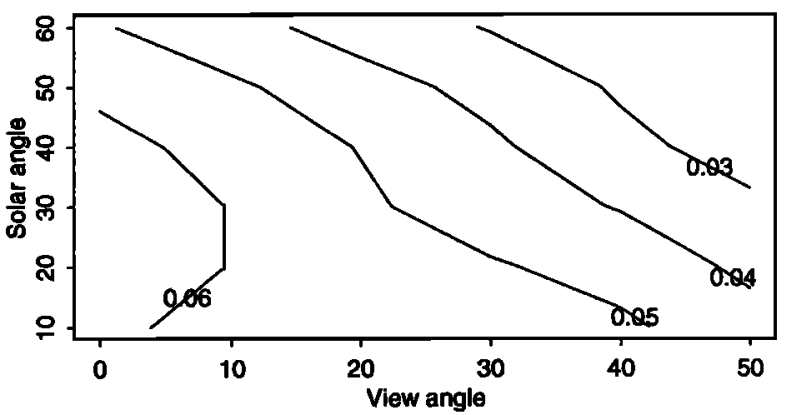

(b)

Figure 10. (a) Variations of the slope $a$ as a function of Sun-sensor geometry. The curves from top to bottom correspond to an increasing solar zenith angle (from $10^{\circ}$ to $60^{\circ}, 10^{\circ}$ interval). (b) Corresponding error isolines. 
SAVANNA : fAPARd $=a N D V I+b$
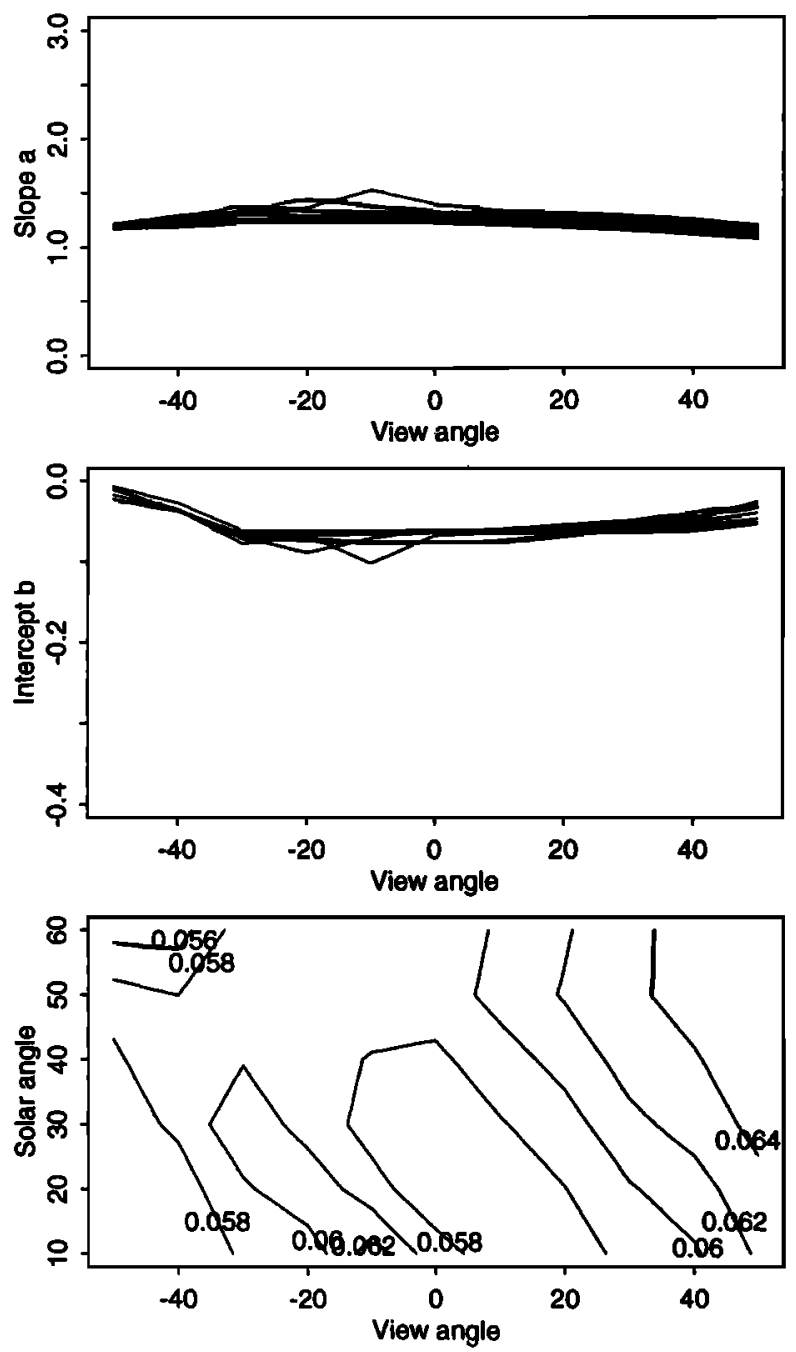

Figure 11. Variations of the (a) slope $a$ and (b) intercept $b$ as a function of Sun-sensor geometry, and (c) the corresponding error isolines. In Figure 11a the curves from top to bottom correspond to an increasing solar zenith angle (from $10^{\circ}$ to $60^{\circ}, 10^{\circ}$ interval). In Figure 11b the curves from top to bottom correspond to a decreasing solar zenith angle (from $60^{\circ}$ to $10^{\circ}, 10^{\circ}$ interval).

cause of the presence of a short herb layer and a low density of vertical protrusions (trees), but its radiometry depends on the fraction of vegetation cover. Nevertheless, different algorithms calculating fAPAR $_{d}$ from atmospherically corrected NOAA vegetation indices have been proposed for each canopy type, and the recommendations in the use of these algorithms are the same for both canopies. The formulation of these algorithms depends on the nature of the satellite data:

1. If only NOAA-AVHRR NDVI archives are available, a global linear relationship is proposed for each canopy type, but this relationship is very approximate (having bad linearity and high scatter) and does not give an accurate fAPAR evaluation (RMSE equals 0.072 for millet and 0.068 for natural vegetation), especially at low vegetation cover.
2. If the reflectances in the red and near-infrared channels are known, we recommended using the algorithms established with MSAVI, rather than NDVI, in order to obtain an accurate fAPAR $_{d}$ estimation, especially for natural vegetation (RMSE equals 0.07 for millet and $\mathbf{0 . 0 4}$ for natural vegetation). The slope of the soil line can be estimated from the model of Baret et al. [1993].

3. If the geometry of the acquisition is known, the slope and intercept of the linear regressions can be parameterized with the Sun and view angles. In the case of millet canopies this parameterization improves greatly the estimation of the AAPAR $_{d}$, and the best results are obtained with MSAVI (RMSE between 0.02 and 0.04). But in the case of natural vegetation this parameterization does not modify globally the accuracy of the fAPAR $_{d}$ estimation (RMSE between 0.03 and 0.05).

4. If the NOAA series permits evaluation of the vegetation index of the background (early image during the dry season), simplified algorithms are then proposed relating fAPAR $_{d}$ to the difference between the canopy VI and the background VI, through a one-parameter model. For millet, when this coefficient is given as a function of the Sun and view angles, the RMSE for MSAVI is between 0.03 and 0.06 , whereas it was around 0.09 when the coefficient was not parameterized. For natural vegetation this coefficient is almost independent of the Sun-view geometry when MSAVI is used; it can be considered as a constant and equal to 2.2 , with the RMSE around 0.07.

\section{SAVANNA : fAPARd $=$ a (MSAVI-MSAVIs)}

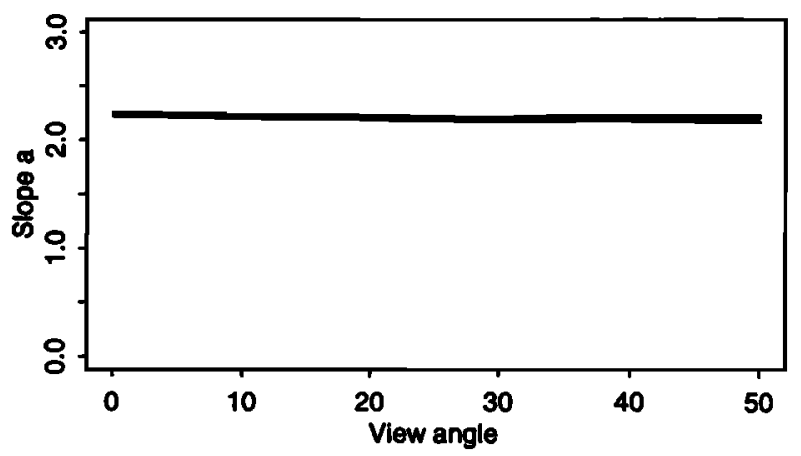

(a)

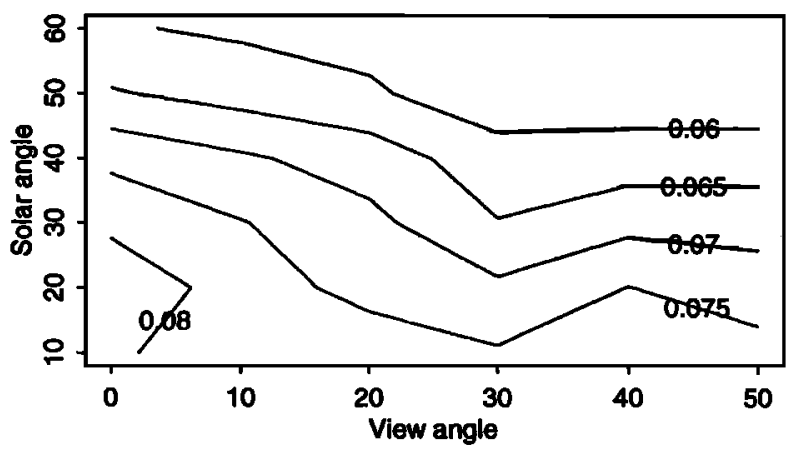

(b)

Figure 12. (a) Variations of the slope $a$ as a function of Sun-sensor geometry. The curves from top to bottom correspond to an increasing solar zenith angle (from $10^{\circ}$ to $60^{\circ}, 10^{\circ}$ interval). (b) Corresponding error isolines. 

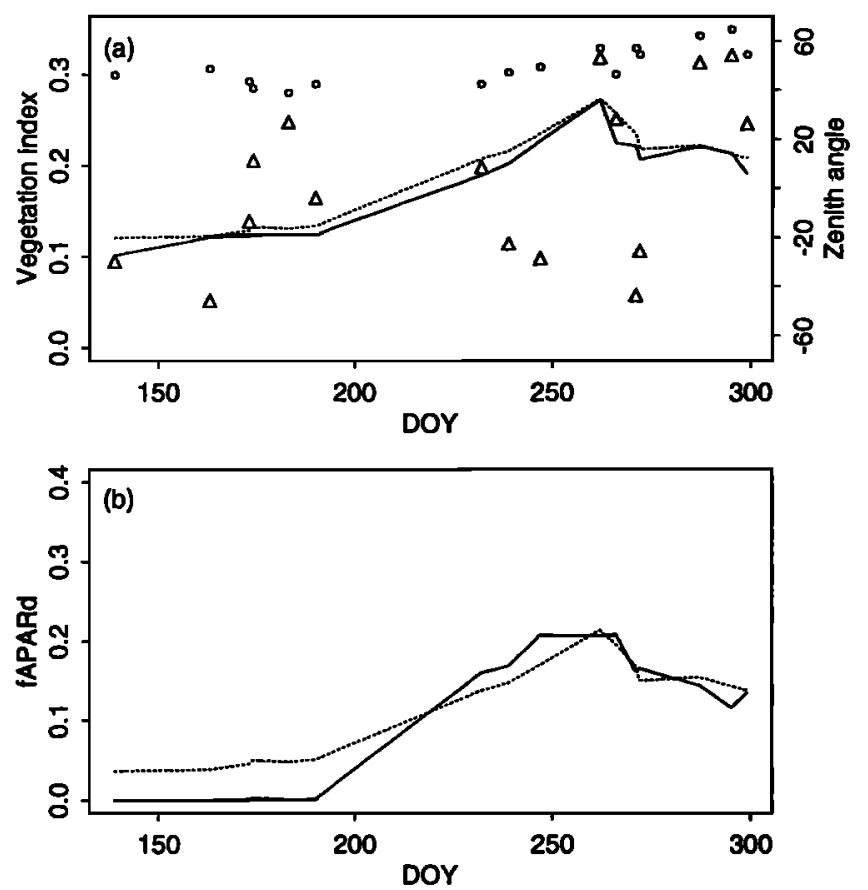

Figure 13. (a) Temporal profile of millet NDVI (dotted line), MSAVI (solid line), and the corresponding solar (circles) and view (triangles) angles, extracted from 1992 NOAA series. (b) Daily fAPAR calculated with fAPAR $_{d}=a\left(\theta_{s}, \theta_{v}\right)$ (MSAVI - MSAVI $)$ (solid line) and calculated with the global relationship fAPAR ${ }_{d}=$ $a$ NDVI $+b$ (dotted line).
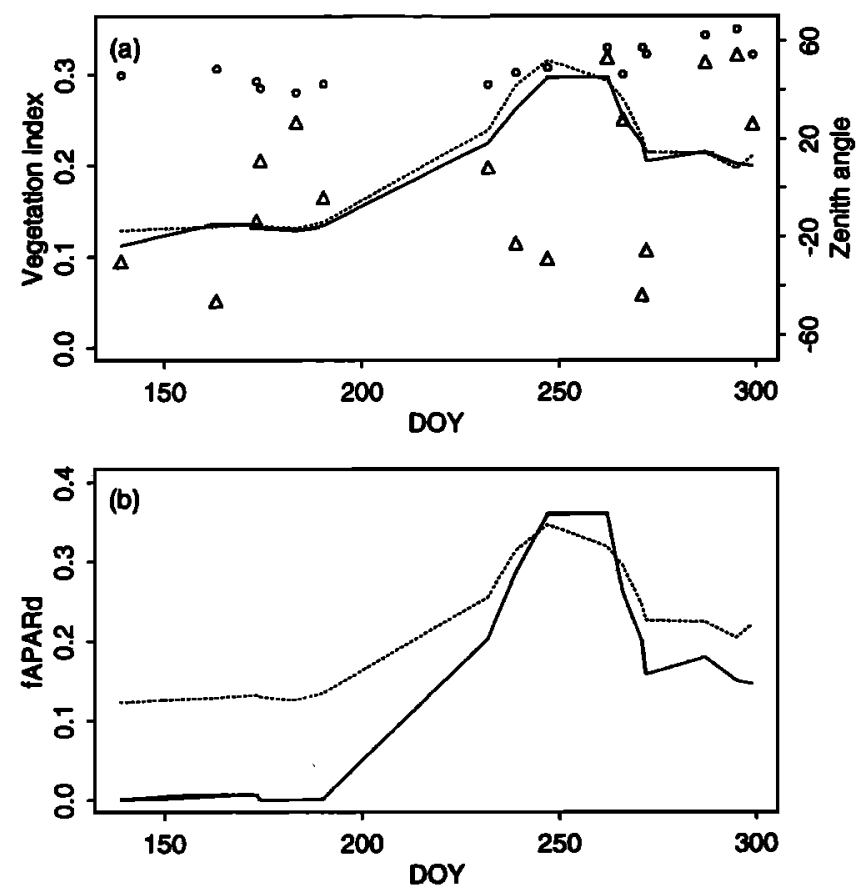

Figure 14. (a) Temporal profile of natural vegetation NDVI (dotted line), MSAVI (solid ligne), and the corresponding solar (circles) and view (triangles) angles, extracted from 1992 NOAA series. (b) Daily fAPAR calculated with fAPAR $_{d}=a\left(\theta_{s}, \theta_{v}\right)$ (MSAVI-MSAVI $)$ (solid line) and calculated with the global relationship fAPAR $_{d}=a$ NDVI $+b$ (dotted line)
Another interesting point of this analysis of the simulations permits definition of the best geometrical configuration for the purpose of this study. High solar and view angles seem to result in linearity and yield accurate fAPAR $_{d}$ estimation in Sahelian vegetation canopies.

Limitations of the radiative transfer model used in this paper must be recognized. For instance, woody components (e.g., branches) and senescent vegetation are not included in the model. In some canopies the optical properties and leaf angle distributions of different plant species (such as crown and understory vegetation) cannot be differentiated. However, the model and the approach adopted in this paper are very powerful and should be able to be used in the future to (1) estimate fAPAR and other biophysical variables of other biomes in the world (such as LAI and cover fraction) from satellite vegetation indices, (2) calibrate vegetation indices at a global scale from other satellite sensors, such as the ones proposed for MODIS [Huete and Liu, 1994], or (3) define sensor or orbital characteristics in order to determine the best geometrical configurations to address a particular application.

Acknowledgments. A.B. was funded by a CNES scientific fellowship. The participation of R.M. was made possible through a NASA grant. Thanks to the Programme National de Télédétection Spatiale for its support, to Hassan Ouaidrari, who provided the NOAA-AVHRR data, and to H. N. Le Houérou for sharing his knowledge on Sahelian vegetation through useful discussion.

\section{References}

Asrar, G., R. Myneni, Y. Li, and E. Kanemasn, Measuring and modeling spectral characteristics of a tallgrass prairie, Remote Sens. Environ., 27, 143-155, 1990.

Asrar, G., R. Myneni, and B. J. Chondhary, Spatial heterogeneity in vegetation canopies and remote sensing of absorbed photosynthetically active radiation: a modeling study, Remote Sens. Environ., 41, 85-103, 1992.

Baret, F., and A. Olioso, Estimation à partir de mesures de réflectance spectrale du rayonnement photosynthétiquement actif absorbé par une culture de blé, Agronomie, 9, 885-895, 1989.

Baret, F., S. Jacquemond, and J. Hanocq, The soil line concept in remote sensing, Remote Sens. Rev., 7, 65-82, 1993.

Bégué, A., Modeling hemispherical and directional radiative fluxes in regular-clumped canopies, Remote Sen. Environ., 40, 219-230, 1992.

Bégué, A., Leaf area index, daily intercepted PAR and spectral vegetation indices: A sensitivity analysis for regularclumped canopies, Remote Sens. Environ., 46, 1-25, 1993.

Bégué, A., J.F. Desprat, J. Imbernon, and F. Baret, Radiation use efficiency of pearl millet in Sahelian zone, Agric. For. Meteorol., 56, 93-110, 1991.

Bégué, A., S. Prince, N. Hanan, and J.L. Roujean, Shortwave radiation budget of Sahelian vegetation, II, Radiative transfer models, Agric. For. Meteorol., 79, 97-112, 1996.

Choudhury, B. J., Relationships between vegetation indices, radiation absorption, and net photosynthesis evaluated by a sensitivity analysis, Remote Sens. Environ., 22, 209$233,1987$.

D'Herbès, J., D. Courault, F. Timouk, and C. Valentin, Spatio-carte des états de surface au 1/200 000, Programme HAPEX-Sahel, ORSTOM Niamey (Niger), 1992. 
Forest, F., F. Affolder, C. Baron, B. Cortier, L. Somé, S. Traoré, and M. Vaksmann, Evaluation et suivi de la production agricole en fonction du climat et de l'environnement (ESPACE), technical report, CIRAD-CA, France, 1993.

Ganapol, B., and R. Myneni, The Fn method for the oneangle radiative transfer equation applied to plant canopies, Remote Sens. Environ., 39, 213-231, 1992.

Goutorbe, J., et al., HAPEX-Sahel: A large scale of study of land-atmosphere interactions in the semi-arid tropics, Ann. Geophy., 12, 53-64, 1994.

Goward, S., and K. Huemmrich, Vegetation canopy PAR absorptance and the normalized difference vegetation index: An assessment using the SAIL model, Remote Sens. Environ., 39, 119-140, 1992.

Hanan, N., and S. Prince, Leaf scale reflectance and transmittance spectra, HAPEX-SAHEL Inform. Syst., CDROM 3, Ground data v3, April, 1996.

Hanan, N., S. Prince, and A. Bégué, Estimation of absorbed photosynthetically active radiation and vegetation net production efficiency using satellite data, Agric. For. Meteorol., 76, 259-276, 1995.

Hapke, B., Bidirectional reflectance spectroscopy, 1, Theory, J. Geophys. Res., 86, 3039-3054, 1981.

Heimann, M., and C. Keeling, A three-dimensional model of atmospheric $\mathrm{CO}_{2}$ transport based on observed winds, 2, Model description and simulated tracer experiments, in Aspects of climate variability in the Pacific and the Western Americas, Geophys. Monogr. Ser., vol. 55, edited by D.H. Peterson, pp. 237-274, AGU, Washington, D.C., 1989.

Huete, A., and H. Liu, An error and sensitivity analysis of the atmospheric- and soil- correcting variants of the NDVI for the MODIS-EOS, IEEE Trans. Geosci. Remote Sens., 32, 897-905, 1994.

Huete, A., and W. van Leeuwen, BRF Spectron CE590 measurements, HAPEX-SAHEL Inform. Syst., CD-ROM 3, Ground data $\nabla 3$, April, 1996.

Jacquemoud, S., F. Baret, and J. Hanocq, Modeling spectral and bidirectional soil reflectance, Remote Sens. Environ., 41, 123-132, 1992.

Kerr, Y., T. Valero, and J. Wagner, AVHRR 1992, HAPEXSahel Inform. Syst., CD-ROM 12, April, 1996.

Le Houréou, H.N., The Grazing Land Ecosystems of the African Sahel, 282 pp., Ecological studies 75, SpringerVerlag, 1989.

Loudjani, P., Apport des données satellitaires en vue de l'estimation de la production primaire nette à l'échelle régionale: Cas de l'Afrique de l'Ouest, thèse de doct., Univ. Orsay-Paris Sud, Paris, France, 1993.

Marshak, A., The effect of the hot-spot on the transport equation in plant canopies, J. Quant. Spectrosc. Radiat. Transfer, 42, 615-630, 1989.

Matthews, E., Global vegetation and land use: New high resolution data bases for climate studies, J. Clim. Appl. Meteorol., 10, 443-487, 1983.

McCree, K., Test of current definitions of photosynthetically active radiation against leaf photosynthesis data, Agric. For. Meteorol., 10, 443-453, 1972.

Myneni, R., Modeling radiative transfer and photosynthesis in three dimensional vegetation canopies, Agric. For. Meteorol., 55, 323-344, 1991.

Myneni, R., and G. Asrar, Radiative transfer in threedimensional atmosphere vegetation media, J. Quant. Spectrosc. Radiat. Transfer, 49, 585-598, 1993.

Myneni, R., and D. Williams, On the relationship between FAPAR and NDVI, Remote Sens. Environ., 49, 200-211, 1994.
Myneni, R., G. Asrar, and S. Gerstl, Radiative transfer in three dimensional leaf canopies, Trans. Theory Stat. Phys., 19, 205-250, 1990.

Myneni, R., A. Marshak, and Y. Knyazikhin, Transport theory for leaf canopies with finite dimensional scattering centers, J. Quant. Spectrosc. Radiat. Transfer, 46, 259-280, 1991.

Myneni, R., G. Asrar, and F. Hall, A three-dimensional radiative transfer method for optical remote sensing of vegetated land surfaces, Remote Sens. Environ., 41, 105-121, 1992.

Myneni, R., V. Gutschick, G. Asrar, and E. Kanemasu, Photon transport in vegetation canopies with anisotropic scattering, I-IV, Agric. For Meteorol, 42, 1-40 and 87-120, 1988.

Onaidrari, H., Estimation de la production primaire nette du mil dans l'écosystème sahélien, thèse de doct., 210 pp., Univ. Paris VII, Paris, France, Oct. 24, 1994.

Poupon, H., Structure et dynamique de la strate ligneuse d'une steppe sahélienne au nord du Sénégal, thèse de doct., Univ. Paris-Sud Orsay, France, 1979.

Price, J., Timing of NOAA afternoon passes, Int. J. Remote Sens., 12, 193-198, 1991.

Prince, S., N. Hanan, and A. Bégué, West-central vegetation structure measurements, HAPEX-SAHEL Inform. Syst. CD-ROM 3, Ground data $\nabla 3$, April, 1996a.

Prince, S., N. Hanan, and A. Bégué, West-central vegetation biomass measurements, HAPEX-SAHEL Inform. Syst., CD-ROM 3, Ground data v3, April, 1996b.

Qi, J., R. Chehbouni, A. Huete, Y. Kerr, and S. Sorooshian, A modified soil adjusted vegetation indes (MSAVI), $R e$ mote Sens. Environ., 48, 119-126, 1994.

Rouse, J., R. Haas, J. Schell, D. Deering, and J. Harlan, Monitoring the vernal advancement of retrogradation of natural vegetation, type III final report, NASA/GSFC, Greenbelt, MD, 1974.

Ruimy, A., B. Sangier, and G. Dedien, Methodology for the estimation of terrestrial net primary production from remotely sensed data, J. Geophys. Res., 99, 5263-5283, 1994.

Sellers, P., C. Tucker, G. Collatz, S. Los, C. Justice, D. Dazlich, and D. Randall, A global 1 by 1 NDVI data set for climate studies, 2., The generation of global fields of terrestrial biophysical parameters from the NDVI, Int. $J$. Remote Sens., 15, 3519-1545, 1994.

Shultis, J., and R. Myneni, Radiative transfer in vegetation canopies with anisotropic scattering, J. Quant. Spectrosc. Radiat. Transfer, 39, 115-129, 1988.

Stewart, R., Modelling radiant energy transfer in vegetation canopies, M.S. thesis, Kansas State Univ., Manhattan, 1990.

Wallace, J., et al., HAPEX-Sahel Southern Super-Site report: An overview of the site and the experimental programme during the intensive observation period in 1992 technical report, Inst. of Hydrol., Wallingford, England, 1994.

A. Bégué, CIRAD-CA, Maison de la Télédétection, 500 rue J.F. Breton, 34093 Montpellier Cedex 5, France (e-mail: begue@cirad.teledetection.f).

R. Myneni, Biospheric Sciences Branch, Code 923, NASA/GSFC, Greenbelt, MD 20771 (e-mail: rmyneni@scarpia.gsfc.nasa.gov).

(Received October 12, 1995; revised March 31, 1996; accepted May 21, 1996.) 